\title{
Nuclear Localizations of the Herpes Simplex Virus Type 1 Tegument Proteins VP13/14, vhs, and VP16 Precede VP22-Dependent Microtubule Reorganization and VP22 Nuclear Import
}

\author{
Jamie C. Yedowitz, $\uparrow$ Anna Kotsakis, $\uparrow$ Elisabeth F. M. Schlegel, and John A. Blaho* \\ Department of Microbiology, Mount Sinai School of Medicine, New York, New York
}

Received 4 October 2004/Accepted 3 December 2004

\begin{abstract}
Herpes simplex virus type 1 (HSV-1) induces microtubule reorganization beginning at approximately $9 \mathrm{~h}$ postinfection (hpi), and this correlates with the nuclear localization of the tegument protein VP22. Thus, the active retention of this major virion component by cytoskeletal structures may function to regulate its subcellular localization (A. Kotsakis, L. E. Pomeranz, A. Blouin, and J. A. Blaho, J. Virol. 75:8697-8711, 2001). The goal of this study was to determine whether the subcellular localization patterns of other HSV-1 tegument proteins are similar to that observed with VP22. To address this, we performed a series of indirect immunofluorescence analyses using synchronously infected cells. We observed that tegument proteins VP13/14, vhs, and VP16 localized to the nucleus as early as $5 \mathrm{hpi}$ and were concentrated in nuclei by $9 \mathrm{hpi}$, which differed from that seen with VP22. Microtubule reorganization was delayed during infection with HSV-1(RF177), a recombinant virus that does not produce full-length VP22. These infected cells did not begin to lose microtubuleorganizing centers until 13 hpi. Repair of the unique long $49\left(U_{L} 49\right)$ locus in HSV-1(RF177) yielded HSV1(RF177R). Microtubule reorganization in HSV-1(RF177R)-infected cells occurred with the same kinetics as HSV-1(F). Acetylated tubulin remained unchanged during infection with either HSV-1(F) or HSV-1(RF177). Thus, while $\alpha$-tubulin reorganized during infection, acetylated tubulin was stable, and the absence of fulllength VP22 did not affect this stability. Our findings indicate that the nuclear localizations of tegument proteins VP13/14, VP16, and vhs do not appear to require HSV-1-induced microtubule reorganization. We conclude that full-length VP22 is needed for optimal microtubule reorganization during infection. This implies that VP22 mainly functions to reorganize microtubules later, rather than earlier, in infection. That acetylated tubulin does not undergo restructuring during VP22-dependent, virus-induced microtubule reorganization suggests that it plays a role in stabilizing the infected cells. Our results emphasize that VP22 likely plays a key role in cellular cytopathology during HSV-1 infection.
\end{abstract}

It currently remains unclear how the tegument and envelope components assemble to create an infectious herpes simplex virus type 1 (HSV-1) virion particle. Many of the HSV-1 tegument proteins that have been studied in the past were shown to localize to the nucleus $(1,12-14,48,50,62)$. Accordingly, it is believed that primary envelopment occurs as the capsid exits the nucleus $(10,26,28,30,69)$. This suggests that one or more tegument proteins may play a role in the primary envelopment process.

VP13/14, vhs, and VP16 are three abundant tegument proteins. Although the function of VP13/14 remains unclear (5, 17, 18, 47, 49, 51, 72, 73), vhs and VP16 have well-documented functions during infection (for a review, see reference 61 ). VP16 is a virion structural protein $(66,68)$ that also functions as a transactivator of immediate early or $\alpha$ genes, acting through a conserved sequence (TAATGARAT) present in all $\alpha$ promoters $(6,58)$. The cellular factors, HCF and Oct-1, bind and transport VP16 and allow VP16 to bind DNA, respectively $(29,32,35,39,40,52,59,67,70,71)$. At later times during infection, VP16 functions to bind vhs, which is responsible for shutting off host protein synthesis immediately upon infection

\footnotetext{
* Corresponding author. Mailing address: Department of Microbiology, Mount Sinai School of Medicine, One Gustave L. Levy Pl., New York, NY 10029-6574. Phone: (212) 241-7319. Fax: (212) 534-1684. E-mail: john.blaho@mssm.edu.

$\dagger$ These investigators contributed equally to the work.
}

$(27,41,60,63)$. Since vhs nondiscriminantly causes degradation of mRNA, VP16 prevents viral transcripts from degradation through binding of vhs $(36,43)$.

VP22 is a posttranslationally modified, nuclear phosphoprotein $(7,23-25,33,37,50,51)$ that contains 301 amino acids and has a predicted molecular weight of 32,000 (46) that is below the size exclusion limit (molecular weight of 40,000 to 45,000 ) for passive diffusion through the nuclear pore (15). VP22 from bovine herpesvirus 1 (31) and HSV-1 (38) contains two computer predicted nuclear localization signal sites that have not been characterized in standard nuclear import assays. Transiently transfected VP22 has been detected in the nuclei of cells $(8,9,21,31)$. Previous characterization of VP22 during synchronized infections showed that it has three phases of subcellular localization: perinuclear-juxtanuclear or juxtanuclear at $5 \mathrm{~h}$ postinfection (hpi), diffuse at $9 \mathrm{hpi}$, and nuclear at 13 hpi (57). The accumulation of VP22 in the cytoplasm prior to 5 hpi suggested that its nuclear localization is regulated during infection. Avitabile and colleagues originally reported that HSV-1 infection induces microtubule reorganization, which occurs at approximately 9 hpi (4). This restructuring correlates with the nuclear localization of VP22 (38). This observation led to the proposal that microtubule reorganization may function as a mechanism to regulate VP22 nuclear localization (38). While microtubules reorganize during infection, it is unclear what maintains the structure of cellular 
cytoskeleton. It has been reported that acetylated tubulin may stabilize cells during depolymerization (55). Thus, this stabilization may represent one mechanism by which cells maintain their structure during infection.

In this study, we sought to determine whether the nuclear localization of other HSV-1 tegument proteins correlates with microtubule reorganization in a manner similar to VP22. Furthermore, we tested whether VP22 played a role in microtubule reorganization. Finally, we investigated which feature of microtubules allows their reorganization without causing the total loss of cellular structural integrity. Our examinations led us to the following conclusions. The nuclear localizations of VP13/14, vhs, and VP16 are not regulated in the same manner as VP22, and they occur independently of HSV-1-induced microtubule reorganization. Acetylated microtubules are unaffected during HSV-1 infection. The absence of full-length VP22 during HSV-1 infection affects the kinetics of microtubule reorganization. These results suggest a unique role for VP22 in HSV-1-induced microtubule reorganization.

\section{MATERIALS AND METHODS}

Cells and virus. African green monkey kidney (Vero) cells were obtained from the American Type Culture Collection and passaged in Dulbecco's modified Eagle medium supplemented with $5 \%$ fetal bovine serum. The HSV-1(F) virus (19) is the prototype wild-type strain we use in our studies. HSV-1(RF177), termed $\mathrm{RF} 177(\Delta 212)$, is a recombinant virus derived from HSV-1(F) that synthesizes the amino-terminal 212 amino acids of VP22 (56). To obtain virus stocks, subconfluent monolayer Vero cells (approximately $3 \times 10^{6}$ cells) were inoculated with virus at a multiplicity of infection (MOI) of 0.01 for $2 \mathrm{~h}$ at $37^{\circ} \mathrm{C}$ in $199 \mathrm{~V}$ medium (Life Technologies) supplemented with $1 \%$ newborn calf serum. The inoculum was then removed, fresh Dulbecco's modified Eagle medium supplemented with $5 \%$ newborn calf serum was added, and the cells were incubated at $37^{\circ} \mathrm{C}$ in $5 \% \mathrm{CO}_{2}$. Virus stocks were prepared once the infection reached a cytopathic effect of $100 \%$, the virus titers on Vero cells were determined, and aliquots were stored at $-80^{\circ} \mathrm{C}$. All MOIs were derived from the number of PFU of virus on Vero cells.

Synchronized infections. Synchronous infections are defined as uniform staining in all cells in a microscopic field at a given time postinfection, as determined by indirect immunofluorescence with antibodies specific for unique HSV-1 polypeptides (57). Vero cells were seeded the day before infection in six-well dishes containing $22-\mathrm{mm}^{2}$ coverslips for indirect immunofluorescence. For synchronized infections, cells were incubated on ice on an orbital shaker at $4^{\circ} \mathrm{C}$ for $15 \mathrm{~min}$ prior to the addition of virus. The cells were then inoculated with virus $(\mathrm{MOI}=15)$ while still on ice and returned to the shaker at $4^{\circ} \mathrm{C}$. After the virus was allowed to adsorb for $1 \mathrm{~h}$, the cells were removed from the ice, $37^{\circ} \mathrm{C}$ medium was added immediately, and the cells were returned to a $37^{\circ} \mathrm{C}$ incubator.

Induction of synchronous infection by adsorption of the inoculum at $4^{\circ} \mathrm{C}$ is routine and has little or no affect on cells in culture. However, it should be noted that there is some evidence that the $4^{\circ} \mathrm{C}$ incubation used to synchronize the infections may have a transient effect on the monolayer cells (57). Cells fixed immediately after the temperature shift to $37^{\circ} \mathrm{C}$ with formaldehyde and permeabilized with acetone have a slightly more diffuse $\alpha$-tubulin staining pattern than that observed in the cells held at $37^{\circ} \mathrm{C}$ (57). This finding is consistent with the fact that the dynamics of polymerization and depolymerization of microtubules are energy dependent and are expected to be reduced at the lower $\left(4^{\circ} \mathrm{C}\right)$ temperature. This apparent change in the $\alpha$-tubulin organization was not observable by $4 \mathrm{hpi}$, and the two sets of cells $\left(4\right.$ versus $\left.37^{\circ} \mathrm{C}\right)$ were indistinguishable based on $\alpha$-tubulin staining (57). Thus, the cells recover from the $4^{\circ} \mathrm{C}$ shock by this time.

Immunological reagents. RGST49 is a rabbit polyclonal antibody (7) and was used at a dilution of 1:500 for indirect immunofluorescence (57). Monoclonal antibody DM 1A specific for $\alpha$-tubulin (55), monoclonal antibody 611B specific for acetylated $\alpha$-tubulin (55), and polyclonal antiserum to tubulin (originally obtained as a generous gift from G. Piperno) were obtained from Sigma and were used at dilutions of 1:500, 1:500, and 1:100, respectively. Anti-VP16 monoclonal (1-21) and polyclonal (V-20) antibodies were purchased from Santa Cruz Biotechnology, Inc., and used at dilution at 1:50 and 1:100, respectively. R220/5 polyclonal antiserum to VP13/14 (49) (a gift of David Meredith) was used at a dilution of 1:100 (38). Anti-vhs polyclonal antibody (a gift of G. Sullivan Read) was used at a dilution of 1:100 (56). All antibody dilutions were made in 1\% bovine serum albumin (BSA; Sigma). Fluorescein isothiocyanate (FITC)-conjugated anti-rabbit immunoglobulin $\mathrm{G}(\mathrm{IgG})$ (heavy plus light chains $[\mathrm{H}+\mathrm{L}]$ ) and Texas red-conjugated anti-mouse IgG $(\mathrm{H}+\mathrm{L})$ were purchased from Vector Lab oratories (Santa Cruz, Calif.) and used at dilutions of 1:300 and 1:150, respectively, in $1 \%$ BSA. AMCA anti-rabbit $\operatorname{IgG}(\mathrm{H}+\mathrm{L})$ was purchased from Vector Laboratories and used at a 1:300 dilution.

Repair of HSV-1(RF177). Replacement of the inserted green fluorescent protein (GFP) marker in HSV-1(RF177) with the wild-type unique long $49\left(\mathrm{U}_{\mathrm{L}} 49\right)$ gene was performed essentially as described previously $(53,56)$. Briefly, purified viral genomic DNA from HSV-1(RF177) was cotransfected into Vero cells (approximately $15 \mu \mathrm{g}$ of total DNA) with pJB175 DNA, a plasmid containing the entire $\mathrm{U}_{\mathrm{L}} 49$ gene locus and appropriate flanking sequences (56). Three sequential sets of clear (nonfluorescent) plaques were picked from fresh Vero cell monolayers, virus stocks were prepared, and virus integrity was analyzed by Southern hybridization and immunoblotting techniques.

Analysis of viral DNA by Southern hybridization. The DNA hybridization protocol used in this study was a modification of one previously described (53, 56). Briefly, approximately $2 \times 10^{6}$ Vero cells were infected with viruses (MOI of $1 \mathrm{PFU} /$ cell); incubated at $34^{\circ} \mathrm{C}$ for approximately 2 days; scraped into the medium; pelted by low-speed centrifugation for $3 \mathrm{~min}$ at $4^{\circ} \mathrm{C}$; resuspended in 0.5 $\mathrm{ml}$ of $150 \mathrm{mM} \mathrm{NaCl}, 10 \mathrm{mM}$ Tris- $\mathrm{HCl}$ ( $\mathrm{pH} 7.5$ ), and $1.5 \mathrm{mM} \mathrm{MgCl}_{2}$ containing $0.2 \% \mathrm{NP}-40$; and pelleted again for $3 \mathrm{~min}$ at $4^{\circ} \mathrm{C}$. The supernatants were transferred to fresh $1.5-\mathrm{ml}$ tubes, and capsids were disrupted by the addition of $5 \mu \mathrm{l}$ of $0.5 \mathrm{M}$ EDTA and $1.8 \mu \mathrm{l} \beta$-mercaptoethanol. This mixture was phenol-chloroform extracted and precipitated from ethanol, and viral DNAs were digested in 30- $\mu \mathrm{l}$ reaction mixtures each containing $2 \mu \mathrm{l}$ of either BamHI or EcoRV (New England Biolabs) for $2 \mathrm{~h}$. Cleaved DNAs were separated in $0.8 \%$ agarose gels and transferred to nylon membranes by capillary action, as recommended by the manufacturer (Bio-Rad). The probe used for the BamF region was pJB175, which contains the PstI-BamHI fragment of the $U_{L} 49$ gene region (56). The BamQ probe was pJB142, which contains the entire BamHI fragment of HSV-1 encompassing the $t k$ gene (56). Probes were labeled with digoxigenin-11-dUTP with a nick translation kit (Roche), and the hybridized fragments were detected with an anti-digoxigenin antibody conjugated to horseradish peroxidase, as recommended by the manufacturer (Roche).

Immunoblotting of infected whole-cell extracts. Whole-cell extracts of infected cells were obtained as follows. Cells were scraped into the medium and collected after low-speed centrifugation. After a single wash $(3 \mathrm{ml})$ with phosphate-buffered saline (PBS) containing the protease inhibitors $0.1 \mathrm{mM}$ phenylmethylsulfonyl fluoride, $0.1 \mathrm{mM} \mathrm{L}$-1-chlor-3-(4-tosylamido)-4-phenyl-2-butanone (TPCK), and $0.01 \mathrm{mM}$ L-1-chlor-3-(4-tosylamido)-7-amino-2-heptanon-hydrochloride (TLCK), the infected cells were then lysed in a solution containing $50 \mathrm{mM}$ Tris- $\mathrm{HCl}$ ( $\mathrm{pH} 7.5$ ), $150 \mathrm{mM} \mathrm{NaCl}, 5 \mathrm{mM}$ EDTA, 0.4\% Triton X-100, $0.1 \mathrm{mM}$ phenylmethylsulfonyl fluoride, $0.1 \mathrm{mM}$ TPCK, and $0.01 \mathrm{mM}$ TLCK and sonicated with a Branson sonifier. The protein concentrations of all cell extracts were determined by a modified Bradford assay (Bio-Rad) as recommended by the vendor. Equal amounts of infected cell proteins (each, $50 \mu \mathrm{g}$ ) were separated in denaturing $15 \% \mathrm{~N}, N^{\prime}$-diallyltartardiamide-acrylamide gels and electrically transferred to nitrocellulose membranes in a tank apparatus (Bio-Rad) prior to immunoblotting with primary RGST49, a rabbit polyclonal antibody directed against a GST-VP22 fusion protein. Secondary goat anti-rabbit antibody conjugated with alkaline phosphatase was purchased from Southern Biotechnology (Birmingham, Ala.). Unless otherwise noted, all biochemical reagents were obtained from Sigma. Nitrocellulose was obtained directly from Schleicher \& Schuell. Prestained protein molecular weight markers were purchased from Life Technologies.

Indirect immunofluorescence and microscopy. Vero cells were prepared for indirect immunofluorescence as previously described $(38,57)$. Briefly, cells rinsed twice in PBS were fixed in $2.5 \%$ methanol-free formaldehyde (Polysciences, Inc.) for $20 \mathrm{~min}$ at room temperature, rinsed twice again in PBS, and permeabilized in $100 \%$ acetone at $-20^{\circ} \mathrm{C}$ for $4 \mathrm{~min}$. Infected cells were incubated for $16 \mathrm{~h}$ in $1 \%$ BSA supplemented with $10 \mu \mathrm{g}$ of pooled human Ig (Sigma) per $\mathrm{ml}$. Treatment with this amount of human Ig was shown by us to be sufficient to neutralize Fc binding by the viral glycoprotein $\mathrm{E}$ ( $\mathrm{gE}$ ) and $\mathrm{gI}(57)$. The primary antibodies used for indirect immunofluorescence studies were diluted as described above and were added for $1 \mathrm{~h}$. After being extensively rinsed with PBS, the appropriate secondary antibody was added and incubated for $45 \mathrm{~min}$. Finally, the cells were preserved with Prolong Antifade (Molecular Probes) as an antibleaching agent, mounted on a fresh glass slide, and sealed with nail polish. All cells were visualized under oil (magnification, $\times 100$ ) with an Olympus IX70/IXFLA inverted fluorescence microscope, and images were acquired at a resolution of 600 to 800 dots per in. with a Sony DKC-5000 digital photo camera linked to 

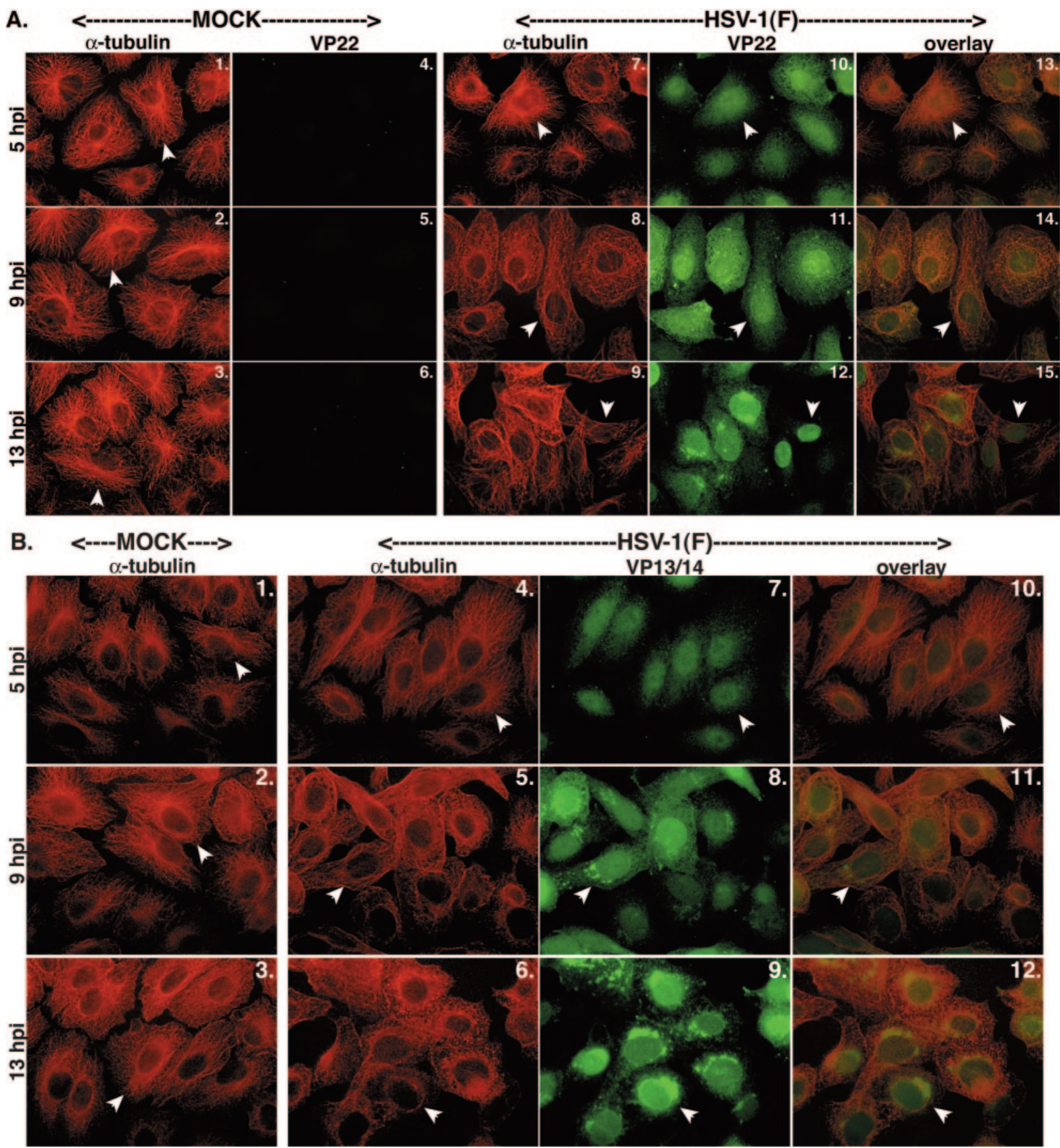

FIG. 1. Nuclear localization of VP22 (A) but not VP13/14 (B) during infection correlates with HSV-1-induced microtubule reorganization. Vero cells were synchronously infected with HSV-1(F) or mock infected, fixed for indirect immunofluorescence at the times indicated, and double stained with anti- $\alpha$-tubulin monoclonal (A and B), anti-VP22 polyclonal (A), or anti-VP13/14 polyclonal (B) antibody as described in Materials and Methods. $\alpha$-Tubulin was visualized with Texas red, and VP22 and VP13/14 were visualized with FITC. Arrowheads in Fig. 1A and B, panels 1 to 3, mark representative cells with detected perinuclear-juxtanuclear MTOCs. Arrowheads in the $\alpha$-tubulin portion of Fig. 1A, panels 7 to 9 , and Fig. 1B, panels 4 to 6, mark cells in which microtubule reorganization occurred during productive HSV-1(F) infection. Thus, in all mock-infected cells and in infected cells at $5 \mathrm{hpi}$, arrowheads mark cells that have not lost their MTOCs. Also in HSV-1(F)-infected cells, arrowheads correspond to the locations of the VP22 and VP13/14 proteins (Fig. 1A, panels 10 to 12, and Fig. 1B, panels 7 to 9). Merged images (overlay) are also shown.

a PowerMac. Raw digital images were saved as tagged image files (TIFs) with Adobe Photoshop, organized into figures with Adobe Illustrator, and printed on a Codonics dye sublimation printer. Quantitation of amounts of VP22 in nuclei was performed with NIH Image densitometric software. The percentage of nuclear VP22 was calculated by the following equation: [nuclear VP22/(nuclear
+ cytoplasmic VP22)] $\times 100$. Arrowheads in the figures indicate representative mock-infected cells or infected cells at 5 hpi with detectable perinuclear-juxtanuclear microtubule-organizing centers (MTOCs). In infected cells at 9 and 13 hpi, arrowheads in the $\alpha$-tubulin panels mark cells in which microtubule reorganization occurred during productive infection. Also in infected cells, arrow- 

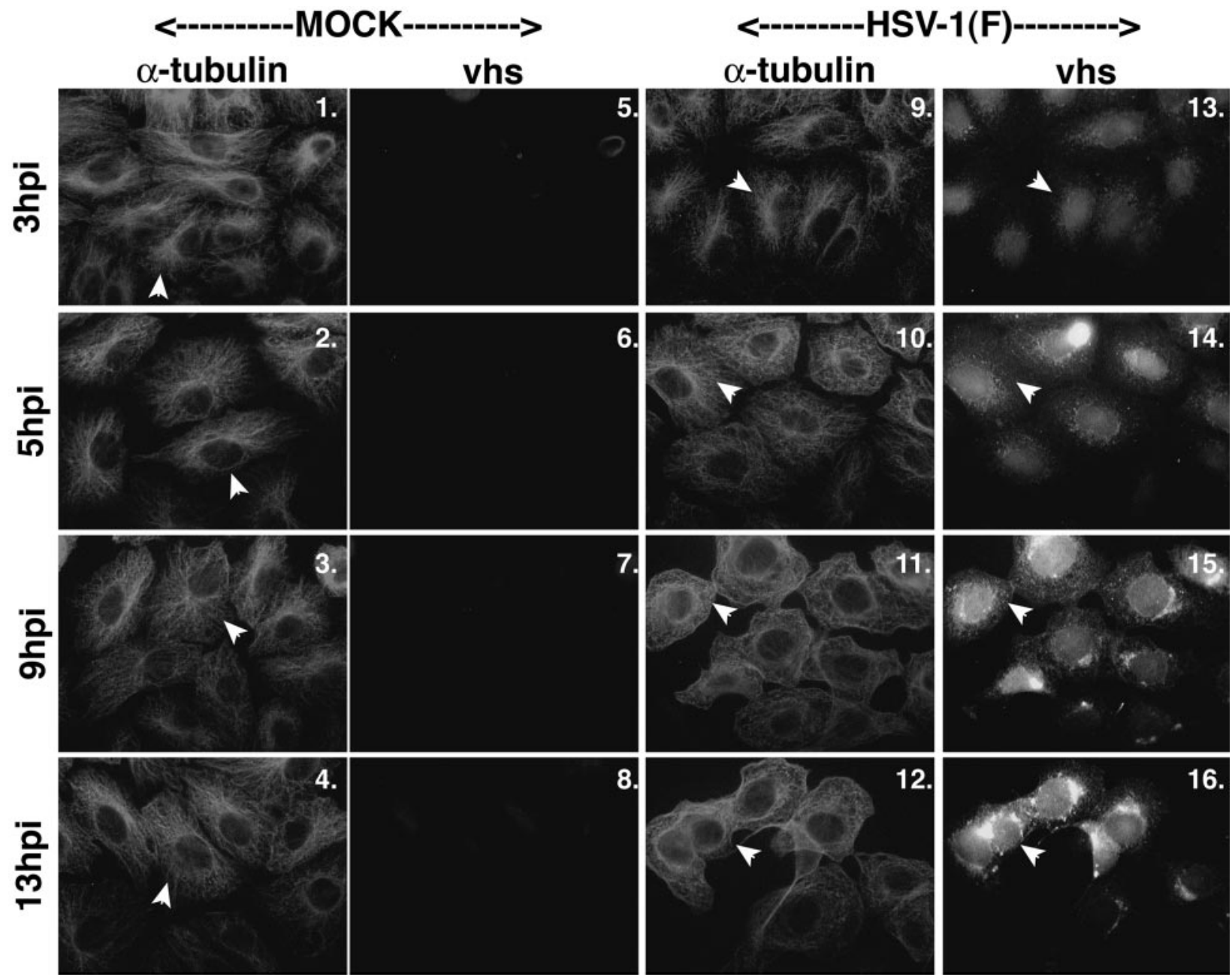

FIG. 2. Microtubule reorganization does not coincide with the nuclear migration of vhs. Vero cells were synchronously infected with HSV$1(\mathrm{~F})$ or mock infected, fixed at the indicated times, and double stained with anti- $\alpha$-tubulin monoclonal and anti-vhs polyclonal antibodies as described in Materials and Methods. Arrowheads in mock-infected cells point to representative cells displaying intact MTOCs (panels 1 to 4). Thus, in all mock-infected cells and in infected cells at 3 and 5 hpi, arrowheads mark cells that have not lost their MTOCs. In HSV-1(F)-infected cells, arrowheads in the $\alpha$-tubulin panels (panels 9 to 12) represent cells in which microtubule reorganization occurred; corresponding arrowheads also show the locations of vhs in these cells (panels 13 to 16). $\alpha$-Tubulin was visualized with Texas red and vhs was visualized with AMCA.

heads correspond to representative cells showing the locations of specific viral proteins.

\section{RESULTS}

Nuclear localization of tegument VP13/14 protein precedes that of VP22 during synchronized HSV-1(F) infection of Vero cells. Previous work by our laboratory showed that HSV-1 induction of microtubule reorganization may function as a mechanism of regulating VP22 nuclear localization (38). The goal of this experiment was to determine whether other tegument proteins might also use the microtubule reorganization process to orchestrate their nuclear localization. Vero cells were synchronously infected with an MOI of $15 \mathrm{PFU} /$ cell with HSV-1(F) as previously described (57) and fixed with formaldehyde-acetone at 5, 9, and 13 hpi for indirect immunofluorescence analyses. The infected cells were double stained with either anti-VP22 or anti-VP13/14 polyclonal antibodies and anti- $\alpha$-tubulin monclonal antibody as described in Materials and Methods. Amounts of nuclear VP22 were determined with densitometric software. The results (Fig. 1) were as follows.

As expected, dense spider web-like projections of $\alpha$-tubulin representing MTOCs were detected at perinuclear-juxtanuclear locations in mock-infected cells at all times tested (Fig. 1A, panels 1 to 3). In contrast, in HSV-1(F)-infected cells, MTOCs were only detected at 5 hpi (Fig. 1A, panel 7). MTOC structures were undetected at 9 and 13 hpi (panels 8 and 9). This phenomenon is consistent with depolymerization that has been previously shown to occur in HSV-1-infected cells and represents microtubule reorganization $(4,38)$. During this reorganization, the microtubules lost their distinct, organized, spider web-like appearance and became dispersed around the periphery of the cells (Fig. 1A, panels 7 to 9). At 5 hpi, VP22 was predominantly localized in the cytoplasm of the cells (Fig. $1 \mathrm{~A}$, panel 10). Densitometric analyses indicated that approximately $25 \%$ of VP22 in the cells at this time point was nuclear; however, this is likely an overestimation due to the fact that 


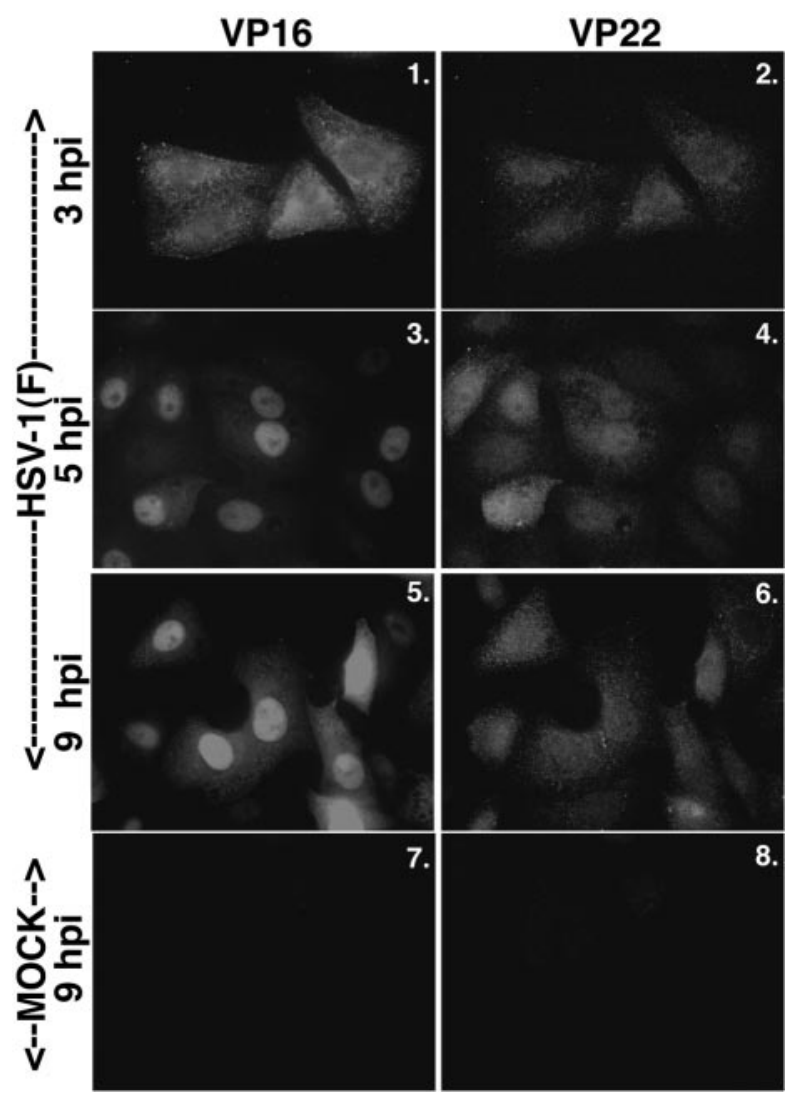

FIG. 3. VP16 nuclear localization precedes that of VP22. Vero cells were synchronously infected with HSV-1(F) or mock infected, fixed at the indicated times, and double stained with anti-VP16 monoclonal and anti-VP22 polyclonal antibodies as described in Materials and Methods. VP16 was visualized with Texas red and VP22 was visualized with FITC.

cytoplasmic VP22, which resides directly over nuclei, is marked as being nuclear. It is important to note that in cells at this time point in which VP22 appeared diffusely throughout the cytoplasm, distinct MTOCs were observed. More (approximately $35 \%$ ) VP22 accumulated in nuclei at 9 hpi (Fig. 1A, panel 11), the time at which reorganization was being detected. At $13 \mathrm{hpi}$, clear concentration of VP22 in nuclei was observed, with almost $75 \%$ of VP22 in nuclei (Fig. 1A, panel 12), and there was complete loss of MTOCs in the infected cells (panel 9). This staining pattern of VP22 at 13 hpi was identical to our earlier observations with confocal microscopy, which demonstrated that VP22 is inside nuclei rather than coating the surface (57). It is of interest to note that we routinely do not observe nucleolar sparing when staining for VP22 (E. F. M. Schlegel et al., unpublished data). The implications of this are currently under investigation. This progressive loss of MTOCs and nuclear translocation of VP22 during infection were visualized in merged images; at 9 hpi, transitional VP22 caused the cytoplasms of cells to appear yellowish orange (Fig. 1A, panel 14), while at 13 hpi, nuclei were green and cytoplasmic microtubules were red (panel 15).

The tegument protein VP13/14 exhibited a different temporal subcellular localization pattern than VP22. At $5 \mathrm{hpi}$, a significant amount of the VP13/14 was detected inside nuclei
(Fig. 1B, panel 7). This was readily observed in the merged images where the cytoplasms of VP13/14-stained cells were essentially all red (Fig. 1B, panel 10). VP13/14 continued to predominate in nuclei at 9 and 13 hpi (panels 8 and 9). Thus, it appears that the localization of VP13/14 did not coincide with microtubule reorganization as it did for VP22, since VP13/14 had accumulated in nuclei at 5 hpi, which was before MTOCs began to break down. Interestingly, we also found that there were bright areas of VP13/14 staining outside nuclei at 9 hpi; these were more pronounced at 13 hpi (Fig. 1B, panels 8 and 9). This may be due to an aggregation or accumulation of the protein later in infection. An alternative explanation for the presence of VP13/14 at these locations is that this may represent detection of cytoplasmic retegumentation during the potential reenvelopment process (reviewed in reference 26). A similar dense perinuclear-juxtanuclear staining also occurred with VP22 but only at the later time point (13 hpi) when it too had localized in nuclei (Fig. 1A, panel 12). The exact nature and biological significance of these intriguing structures are currently unknown.

From these experiments, we can conclude that VP13/14 has a different temporal subcellular localization pattern than VP22. Accordingly, the time frame of VP13/14 nuclear localization does not appear to correlate with HSV-1-induced microtubule reorganization as it does for VP22, inasmuch as VP13/14 is already in nuclei before complete loss of MTOCs occurs.

Nuclear localizations of vhs and VP16 are independent of VP22 nuclear localization and microtubule reorganization. The observation that the nuclear localization of VP13/14 differed from that of VP22 raised the question of how other tegument proteins behaved during HSV-1 infection. In this set of experiments, we looked at two other tegument proteins, vhs and VP16, to see whether their subcellular localizations were similar to either those of VP22 or VP13/14. In the first series, Vero cells were either mock infected or HSV-1(F) infected at an MOI of $15 \mathrm{PFU} /$ cell; at 3, 5, 9, and $13 \mathrm{hpi}$, the Vero cells were stained for anti- $\alpha$-tubulin and anti-vhs by indirect immunofluorescence as described in Materials and Methods. Since the previous experiments showed that VP13/14 began localizing to nuclei earlier than VP22 at 5 hpi, we looked at cells beginning at $3 \mathrm{hpi}$ in this experiment. The results (Fig. 2) were as follows.

As expected, there were MTOCs at all time points, and $\alpha$-tubulin was organized in mock-infected cells (Fig. 2, panels 1 to 4). During HSV-1(F) infection, intact MTOCs were detected at 3 and 5 hpi (panels 9 and 10), as expected, but not at 9 and 13 hpi (panels 11 and 12). These findings are consistent with the results shown in Fig. 1.

In HSV-1(F)-infected cells at 3 and 5 hpi, vhs was observed to be mainly nuclear (Fig. 2, panels 13 and 14). At 9 and 13 hpi, the subcellular localizations of vhs were almost completely nuclear (Fig. 2, panels 15 and 16). This pattern was similar to that of VP13/14 (Fig. 1B, panels 8 and 9). From this experiment, we can conclude that the tegument protein vhs behaves similarly to VP13/14 and localizes to the nucleus prior to $9 \mathrm{hpi}$. This time frame is sooner than that for VP22, which was completely nuclear at $13 \mathrm{hpi}$. Thus, vhs also localized to nuclei prior to microtubule reorganization, suggesting that, like that 

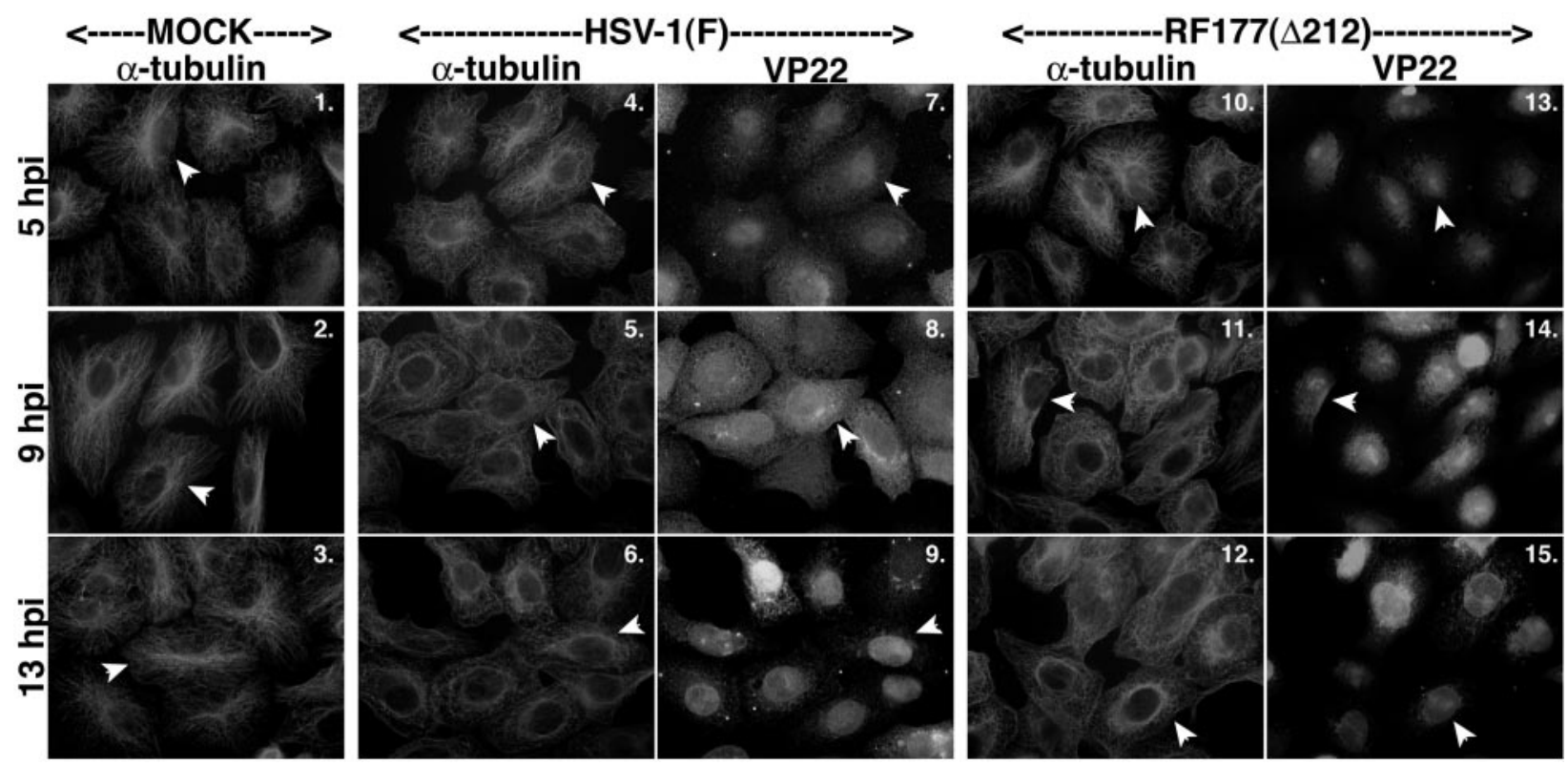

FIG. 4. Microtubule reorganization is delayed during infection with HSV-1(RF177), a recombinant virus which expresses a truncated form of VP22 ( $\Delta 212)$. Vero cells were synchronously infected with HSV-1(F) or HSV-1(RF177), fixed at the indicated times, and analyzed by indirect immunofluorescence by double staining with anti- $\alpha$-tubulin monoclonal and anti-VP22 polyclonal antibodies as described in Materials and Methods. $\alpha$-Tubulin was visualized with Texas red. VP22 was visualized with FITC during HSV-1(F) infection and with AMCA during HSV1(RF177) infection. $\Delta 212$ is the truncated form of VP22 expressed by HSV-1(RF177). Arrowheads in $\alpha$-tubulin panels point to either representative cells with an intact MTOC or cells where the MTOC has been lost. Thus, in all mock-infected cells and in infected cells at 5 hpi, arrowheads mark cells that have not lost their MTOCs. Corresponding infected cells producing full-length and truncated VP22 ( $\Delta 212)$ are also marked by arrowheads.

of VP13/14, its nuclear localization was not dependent on the restructuring process.

In the second series of experiments, the goal was to determine whether VP16's nuclear localization differed from that of VP22. Infections were performed as described above for vhs, but instead of using an anti- $\alpha$-tubulin antibody, we used an antibody to VP16 instead. By using these antibodies, we were able to see the subcellular localizations of both tegument proteins within the same cell. In control experiments, we compared both polyclonal and monoclonal antibodies specific for VP16 and observed that the monoclonal antibody gave superior signals (data not shown). Thus, to compare the kinetics of the VP16 and VP22 in the same infected cell, we made use of the monoclonal VP16 and the polyclonal VP22 antibodies (Fig. 3).

At 3 hpi, VP16 was diffuse throughout the cell (Fig. 3, panel 1), while VP22 was detected at very low levels (panel 2). At 5 hpi, VP16 was concentrated in nuclei (panel 3). In other earlier studies, we also detected the synthesis of VP16 at times as early as 3 to 5 hpi (2). VP22 staining at 5 hpi (Fig. 3, panel 4) was comparable to that shown above (Fig. 1A, panel 10), where the staining was spread out over the cell, mainly in the cytoplasm. At 9 hpi, VP16 remained predominantly nuclear (Fig. 3, panel 5), with some VP16 protein detected in the cytoplasm. Cytoplasmic VP16 may reflect similar late stage localizations as observed with VP13/14 above.

These results indicate that the kinetics of VP16 nuclear localization was different from that of VP22, but similar to that of VP13/14 and vhs. VP16 also migrated to and accumulated in nuclei prior to microtubule reorganization (data not shown).
From these experiments, we conclude that the nuclear localization of VP13/14, vhs, and VP16 occur independently of the nuclear translocation of VP22 and HSV-1 stimulated microtubule reorganization.

Microtubule reorganization is delayed during HSV1(RF177) infection. Earlier reports from our laboratory $(8,56$, $57)$ and others $(22,45)$ suggested that VP22 may associate with microtubules. To determine whether the absence of full-length VP22 affects microtubule reorganization during productive infection we utilized the recombinant virus HSV-1(RF177), which synthesizes only the amino-terminal 212 amino acids of VP22, termed $\Delta 212$ (57). HSV-1(RF177) is capable of assembling infectious virion particles and has essentially the same replication kinetics as its parent, HSV-1(F), at early infection times (56). Vero cells were synchronously mock, HSV-1(F), or HSV-1(RF177) infected and analyzed at 5, 9, and 13 hpi by indirect immunofluorescence with anti- $\alpha$-tubulin and antiVP22 antibodies as described in Materials and Methods. The results are shown in Fig. 4.

As expected, dense MTOCs were detected at perinuclearjuxtanuclear locations in mock-infected cells at all times tested (Fig. 4, panels 1 to 3) and were only detected at 5 hpi (panel 4) in HSV-1(F)-infected cells; MTOC structures disappeared at 9 hpi (panel 5) and were reorganized $(4,38)$ at 13 hpi (panels 6 and 3). At 13 hpi, VP22 was almost exclusively found in nuclei (panel 9).

In HSV-1(RF177)-infected cells, the microtubules looked the same as those in mock-infected cells at 5 hpi (Fig. 4, panels 10 and 1). The microtubules in HSV-1(RF177)-infected cells appeared more similar to those in mock-infected cells than in 


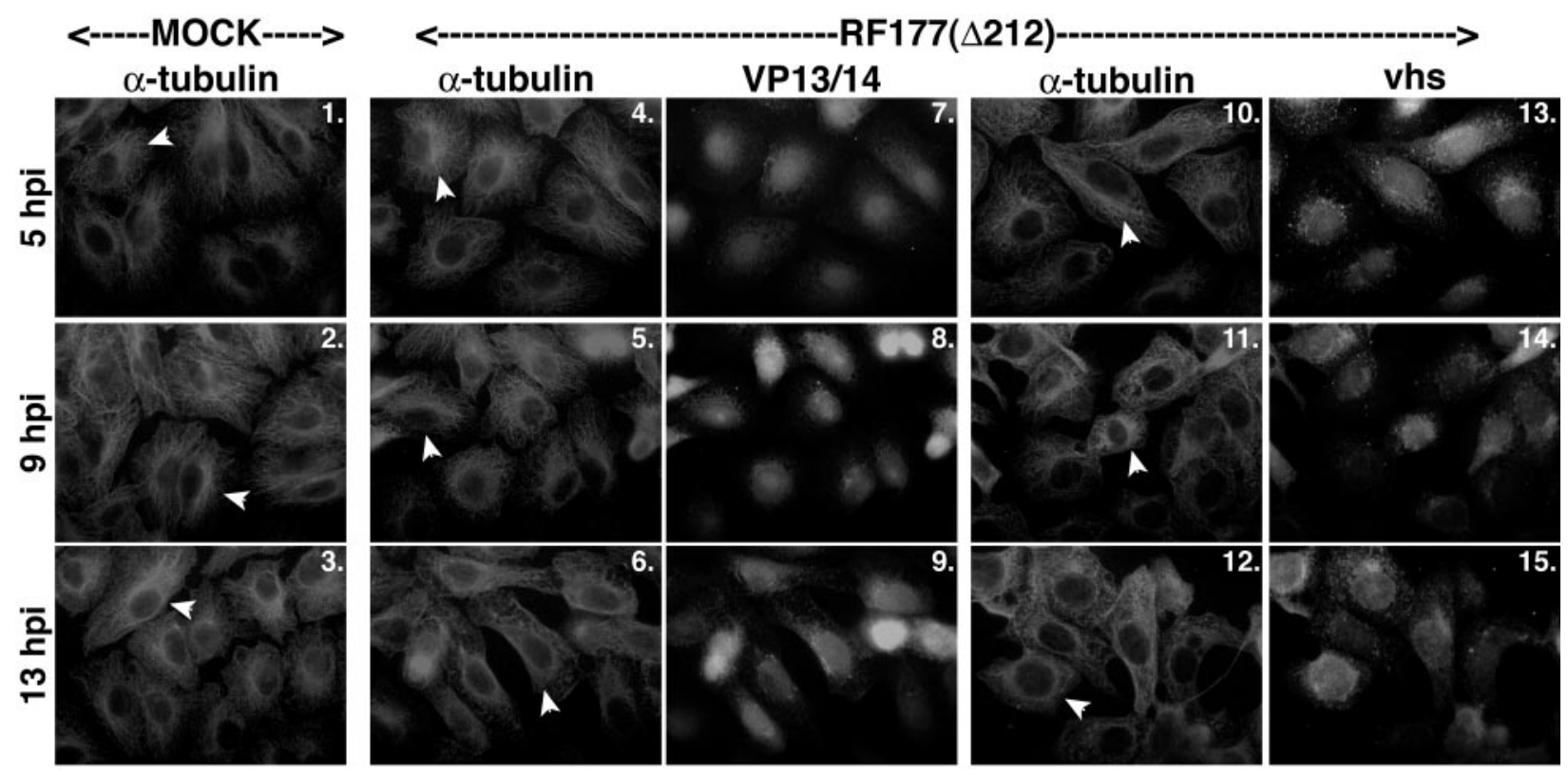

FIG. 5. Nuclear localization of VP13/14 and vhs during HSV-1(RF177) infection. Vero cells were synchronously infected with HSV-1(RF177) or mock infected, fixed at the indicated times, and analyzed with indirect immunofluorescence by double-staining using anti- $\alpha$-tubulin monoclonal and anti-VP13/14 or vhs polyclonal antibodies as described in Materials and Methods. $\alpha$-tubulin was visualized with Texas Red. VP13/14 and vhs were visualized with AMCA. Arrowheads in $\alpha$-tubulin panels point to representative cells either with an intact MTOC or cells whose MTOCs have been lost. Thus, in all mock-infected cells and in infected cells at 5 hpi, arrowheads mark cells that have not lost their MTOCs. " $\Delta 212$ " indicates that RF177 synthesizes a truncated form of VP22.

HSV-1(F)-infected cells at 9 hpi (compare panels 11, 2, and 5); infected cells with intact MTOCs could be detected in HSV1(RF177)-infected cells at 9 hpi. The important observation here is that microtubules in HSV-1(RF177)-infected cells at 9 hpi (panel 11) were similar in appearance to those in HSV1(F)-infected cells at 13 hpi (panel 6). At 13 hpi, the HSV1(RF177)-infected cells appeared to more closely resemble the HSV-1(F)-infected cells (compare panels 12 and 6), but structures resembling MTOCs could still be observed with HSV1(RF177) (panel 12). Such structures were never detected with HSV-1(F) at 9 or 13 hpi. Thus, microtubule reorganization seemed to be delayed after infecting cells with a virus producing a truncated VP22 compared to that of wild-type HSV-1(F) infection. This observation suggested that full-length VP22 may be necessary for efficient HSV-1-induced microtubule reorganization.

In addition, we noticed that the subcellular localization of the truncated form of VP22, $\Delta 212$, was different from that of the full-length protein. At $9 \mathrm{hpi}, \Delta 212$ had almost completely localized to the nucleus while VP22 was diffuse (Fig. 4, panels 14 and 8). These results represent the first characterization of the subcellular localization of this truncated form of VP22 during the course of synchronized HSV-1(RF177) infection. This apparently unregulated nuclear import may be the consequence of $\Delta 212$ being a smaller form of VP22; it is conceivable that $\Delta 212$ is simply small enough to enter nuclei by passive diffusion. Intriguingly, the question remains as to why $\Delta 212$ accumulates in the nucleus at all (56). This finding suggests that the amino portion of VP22 may possess a nucleus retention-like signal. Additional studies are needed to determine the mechanism by which this form of VP22 localizes to nuclei.
For the purpose of this study, $\Delta 212$ served as a marker of infection for us.

Since we saw that MTOCs have a delayed reorganization in cells that are infected with the recombinant HSV-1(RF177) virus, we wanted to see how other tegument proteins would be affected. Two identical sets of experiments were performed to visualize the localization patterns of tegument proteins VP13/14 and vhs with respect to microtubule breakdown and reorganization when infected with the HSV-1(RF177) virus. Vero cells were either mock or HSV-1(RF177) infected at an MOI of 15 PFU/cell; stained with anti- $\alpha$-tubulin, anti-VP13/14, or anti-vhs antibodies at 5, 9, and $13 \mathrm{hpi}$; and visualized by indirect immunofluorescence as described in Materials and Methods. The results (Fig. 5) were as follows.

As expected, MTOCs were present in all mock-infected cells (Fig. 5, panels 1 to 3). MTOCs were present in the HSV1(RF177)-infected cells at both the 5- and 9-hpi time points (panels 4 and 10 and 5 and 11, respectively). At 13 hpi, MTOCs were not detected (panels 6 and 12). Thus, there was a delay in the reorganization process with HSV-1(RF177), consistent with the results shown in Fig. 4.

VP13/14 and vhs both localized to nuclei at 5 hpi in the HSV-1(RF177)-infected cells (Fig. 5, panels 7 and 13). At 9 and $13 \mathrm{hpi}$, the subcellular localizations of VP13/14 and vhs were nuclear (panels 8 and 14 and 9 and 15, respectively). These subcellular localizations are consistent with the patterns observed in HSV-1(F)-infected cells (Fig. 1B and 2). These results indicate that the nuclear localizations of VP13/14 and vhs were unaffected by the absence of full-length VP22, as they both migrated with the same localization patterns in HSV1(F)- and HSV-1(RF177)-infected cells. These findings sup- 


\section{A. Schematic representation of viruses}

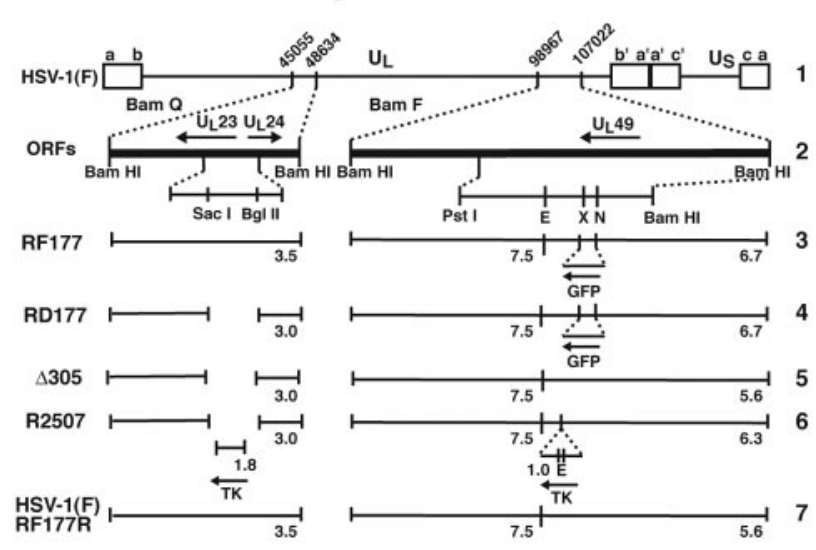

C. Autoradiogram - Bam F probe

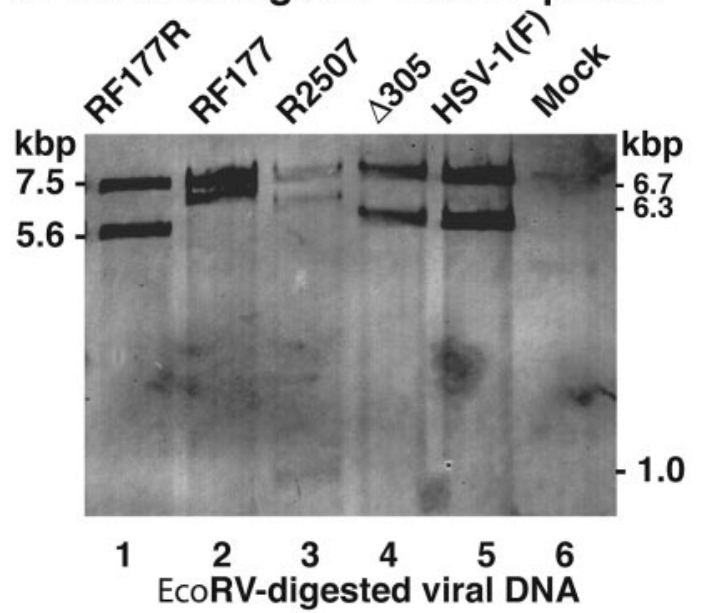

B. Autoradiogram - Bam Q probe

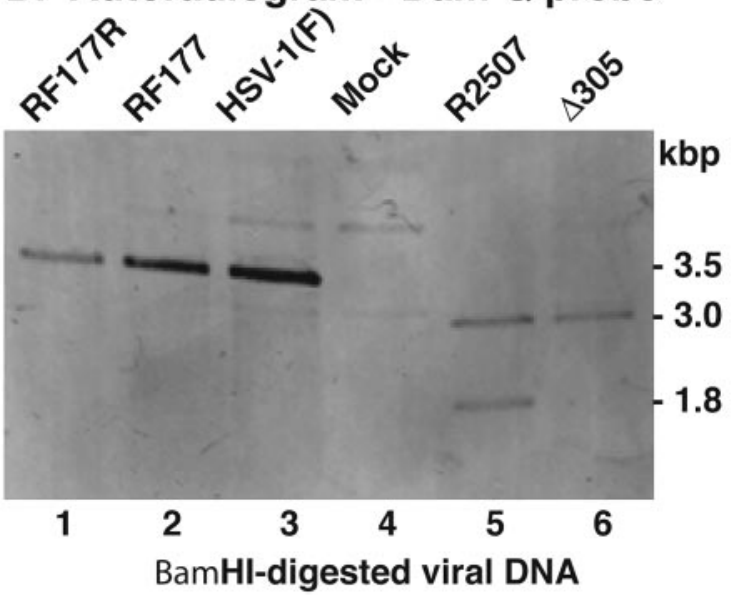

D. Immunoblot - RGST49 pAb

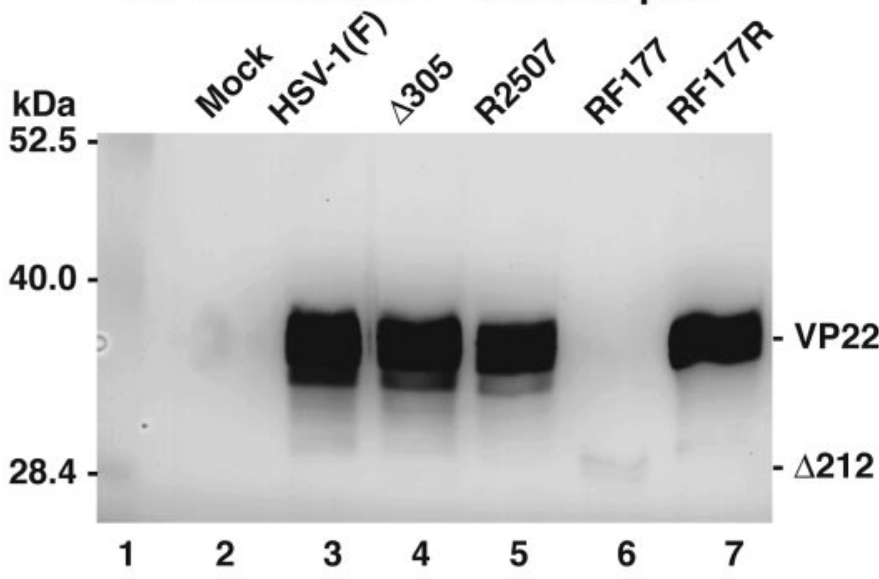

FIG. 6. Repair of HSV-1(RF177). (A) Schematic representation of viruses used in this study. Line 1, wild-type HSV-1 in the prototype orientation. The unique long $\left(\mathrm{U}_{\mathrm{L}}\right)$, unique short $\left(\mathrm{U}_{\mathrm{S}}\right)$, terminal repeat segments $\left(\mathrm{a}, \mathrm{b}, \mathrm{c}, \mathrm{a}^{\prime}, \mathrm{b}^{\prime}\right.$, and $\left.\mathrm{c}^{\prime}\right)$, and relevant nucleotide numbers are indicated. Line 2, relevant predicted open reading frames in the BamQ and BamF fragments of the viral genome. Locations of SacI, BglII, PstI, EcoRV (E), XhoI (X), and NsiI (N) restriction sites are indicated. Lines 3 to 7, expected fragments (numbers are kilobase pairs) following hybridization with either BamQ or BamF probes for RF177, RD177, 4305 , R2507, HSV-1(F), and RF177R viruses. (B and C) Autoradiographic images of viral DNAs. Southern hybridizations of BamHI-digested viral DNA were performed using BamQ- or BamF-specific probes as described in Materials and Methods. The sizes of viral DNA fragments hybridizing to the probes are indicated in the margins. (D) Immune reactivities of infected cell proteins. Whole-cell extracts of mock-, HSV-1(F), $\Delta 305$, R2507, RF177, HSV-1(F), and RF177R-infected Vero cells were prepared at $24 \mathrm{hpi}$, separated in a denaturing gel, transferred to nitrocellulose, and probed with anti-VP22 polyclonal antibody (RGST49 pAb). The locations of molecular mass markers (in kilodaltons) are indicated in the left margin. $\Delta 212$ is the truncated form of VP22 synthesized by RF177.

port the model that the nuclear localizations of VP13/14 and vhs are not dependent on microtubule reorganization.

Restoration of full-length VP22 in HSV-1(RF177) recovers microtubule reorganization. The results shown in Fig. 4 and 5 suggested that there was a delay in the MTOC breakdown phenomenon during infection with HSV-1(RF177). To support our prediction that this was due to the loss of full-length VP22, we wished to determine the effects on microtubule reorganization using an HSV-1(RF177) repair virus (Fig. 6). We expected that the pattern of reorganization observed with such a virus would be similar to that seen during a wild-type HSV$1(\mathrm{~F})$ infection.

We replaced the truncated form of the $U_{L} 49$ gene with a wild-type copy by standard marker transfer methods and plaque screening as described in Materials and Methods. The integrity of the repaired virus, termed HSV-1(RF177R), was assessed by Southern hybridization. The results indicated that the restriction endonuclease cleavage patterns of HSV1(RF177R) DNA at these two loci were identical to that of the parental HSV-1(F) (Fig. 6B, lanes 1 and 3, and C, lanes 1 and 5). Finally, Vero cells were infected with HSV-1(F), HSV1( $\Delta 305)$, HSV-1(R2507), HSV-1(RF177), or HSV-1(RF177R) at an MOI of $5 \mathrm{PFU} /$ cell. Whole-cell extracts were prepared, separated on a denaturing gel, transferred to nitrocellulose, and probed with an anti-VP22 antibody. The results indicated that HSV-1(RF177R) synthesized full-length VP22 (Fig. 6D, lanes 3, 5, and 7). Based on these results, we conclude that the $\mathrm{U}_{\mathrm{L}} 49$ locus has been repaired in HSV-1(RF177R). 


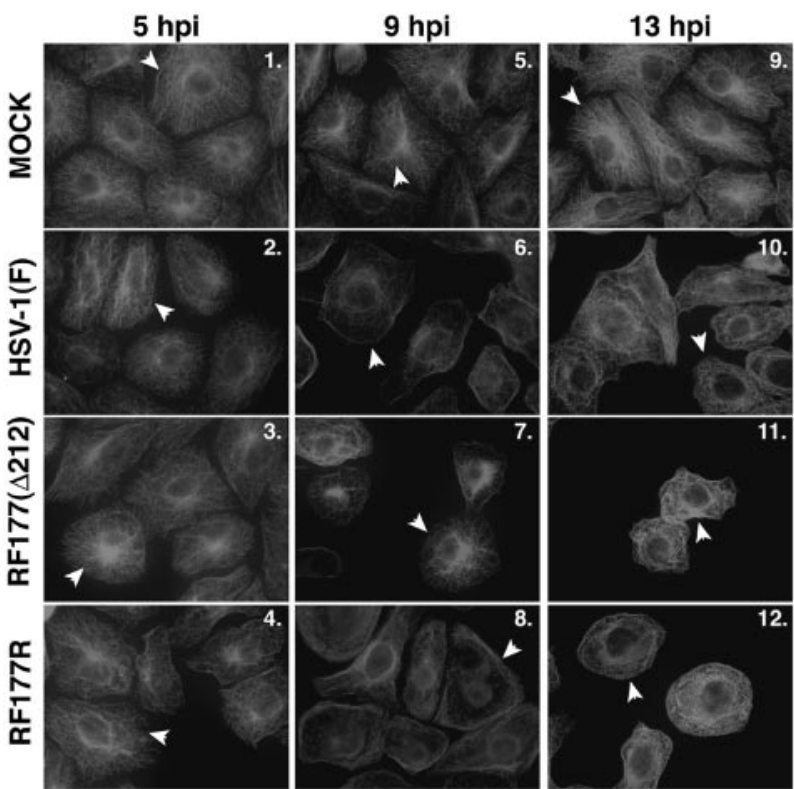

FIG. 7. Microtubule reorganization is delayed in cells infected with HSV-1(RF177), but not the repair virus HSV-1(RF177R). Vero cells were synchronously infected with HSV-1(F), HSV-1(RF177), or HSV1(RF177R); fixed at the indicated times; and analyzed with indirect immunofluorescence by staining with anti- $\alpha$-tubulin antibody as described in Materials and Methods. $\alpha$-Tubulin was visualized with Texas red. Arrowheads in $\alpha$-tubulin panels point to either representative cells with an intact MTOC or cells whose MTOCs have been lost. Thus, in all mock-infected cells and in infected cells at $5 \mathrm{hpi}$, arrowheads mark cells that have not lost their MTOCs. $\Delta 212$, RF177 synthesizes a truncated form of VP22.

Next, we set out to characterize the reorganization of microtubules during infection with HSV-1(RF177R) and compared its kinetics to that of HSV-1(F) and HSV-1(RF177). Vero cells were either mock infected or infected with HSV1(F), HSV-1(RF177), or HSV-1(RF177R) at an MOI of 15 $\mathrm{PFU} /$ cell; fixed at 5, 9, and $13 \mathrm{hpi}$; and stained with an anti- $\alpha$ tubulin antibody. The results (Fig. 7) are as follows. Distinct, intact MTOCs were present at all time points in the mockinfected cells (Fig. 7, panels 1, 5, and 9). Bright-staining MTOCs were seen in each infected cell at $5 \mathrm{hpi}$, as expected (Fig. 7, panels 2 to 4). In the HSV-1(F)- and HSV-1(RF177R)infected cells, there was a loss of MTOCs at 9 and $13 \mathrm{hpi}$ (panels 6 and 10 and 8 and 12, respectively). In HSV1(RF177)-infected cells, the pattern of MTOCs breakdown was delayed; MTOCs were present at 5 hpi (panel 3) and at 9 hpi (panel 7) but not at 13 hpi (panel 11). In summary, none of the cells infected with either wild-type HSV-1(F) or the repair virus HSV-1(RF177R) at 9 hpi had detectable MTOCs (Fig. 7, panels 6 and 8 ) while 4 of $5(80 \%)$ had MTOCs with HSV1(RF177) (panel 7). Based on these results, we conclude that full-length VP22, which is synthesized in both HSV-1(F) and HSV-1(RF177R), is necessary for the efficient breakdown of MTOCs at 9 hpi.

Acetylated tubulin remains stable during HSV-1 infection. During the course of our original investigation on HSV-1induced microtubule reorganization, we utilized the tubulin depolymerizing drug, nocodazole (38). Nocodazole causes treated cells to round up and pull away from the dish, since the structural integrity of the cytoskeleton is compromised as a result of the depolymerizing tubulin. Consequently, these cells are unable to be infected efficiently (38). We were curious to understand why HSV-1-induced microtubule reorganization does not cause this same type of cell phenotype.

Piperno and colleagues showed that under depolymerizing conditions, acetylated $\alpha$-tubulin present in microtubules are more stable than the majority of cytoplasmic microtubules (55). It was also reported in indirect immunofluorescence studies that VP22 transiently expressed in COS- 1 cells colocalizes with microtubules that may contain acetylated tubulin (22). Thus, we set out to characterize acetylated tubulin during the course of a synchronized HSV-1(F) infection. Two sets of experiments were performed. In the first series (Fig. 8A), Vero cells were mock infected or infected at an MOI of $15 \mathrm{PFU} /$ cell with HSV-1(F). At 5, 9, and $13 \mathrm{hpi}$, they were fixed and analyzed with indirect immunofluorescence by double staining with anti-VP22 and anti-acetylated tubulin antibodies as described in Materials and Methods.

In all of the mock-infected cells, staining for acetylated tubulin appeared similar to what we had observed above for $\alpha$-tubulin, except that there were less-intense signals in the areas of the MTOCs, combined with bright staining surrounding the nuclei (Fig. 8A, panels 1 to 3 ). During HSV-1(F) infection at $5 \mathrm{hpi}$, acetylated tubulin stained brightly at the MTOC areas around the nuclei (Fig. 8A, panel 4), and it was identical to that in mock-infected cells (panels 4 and 1). At 9 hpi, the staining pattern of acetylated tubulin did not change and remained similar to that at $5 \mathrm{hpi}$, with bright staining surrounding the nucleus (compare panels 5 and 4). At 9 hpi, VP22 was diffuse in cells (panel 8) and acetylated tubulin was still very apparent around the nuclei (panel 5). In the merged images with VP22 and acetylated tubulin, there was bright staining around the nucleus, which was observed as an orange or bright yellow ring (panel 11). This staining pattern was different from that observed with merged images of VP22 and $\alpha$-tubulin at $9 \mathrm{hpi}$, where there was yellow staining throughout the cell with no bright areas of red (compare Fig. 8A, panel 11, and Fig. 1A, panel 14). At 13 hpi, the acetylated tubulin patterns retained the same appearances observed at earlier times of infection (compare Fig. 8A, panels 6, 5, and 4), showing brighter staining mostly surrounding the nuclei, and VP22 was completely nuclear (panel 9). This was characterized in the merged images by bright red staining outside green nuclei (panel 12). Thus, we observed that VP22 underwent its three phases of subcellular localization, as expected (57), and acetylated tubulin remained unchanged throughout $13 \mathrm{~h}$ of infection.

While the acetylated tubulin did not significantly change its pattern or intensity of staining throughout infection, its intensity appeared slightly different than the mock-infected cells at 13 hpi (panels 3 and 6). This likely reflects the fact that in mock-infected cells no microtubule reorganization occurs and MTOCs are still intact. Accordingly, the staining pattern would appear brighter, since there may be more acetylated tubulin present. In addition, we occasionally noticed that the acetylated microtubule pattern in the HSV-1(F)-infected cells at 13 hpi was slightly broadened in some cells. This may reflects the fact that the cells are productively infected and could be a consequence of the cytopathic effect. 

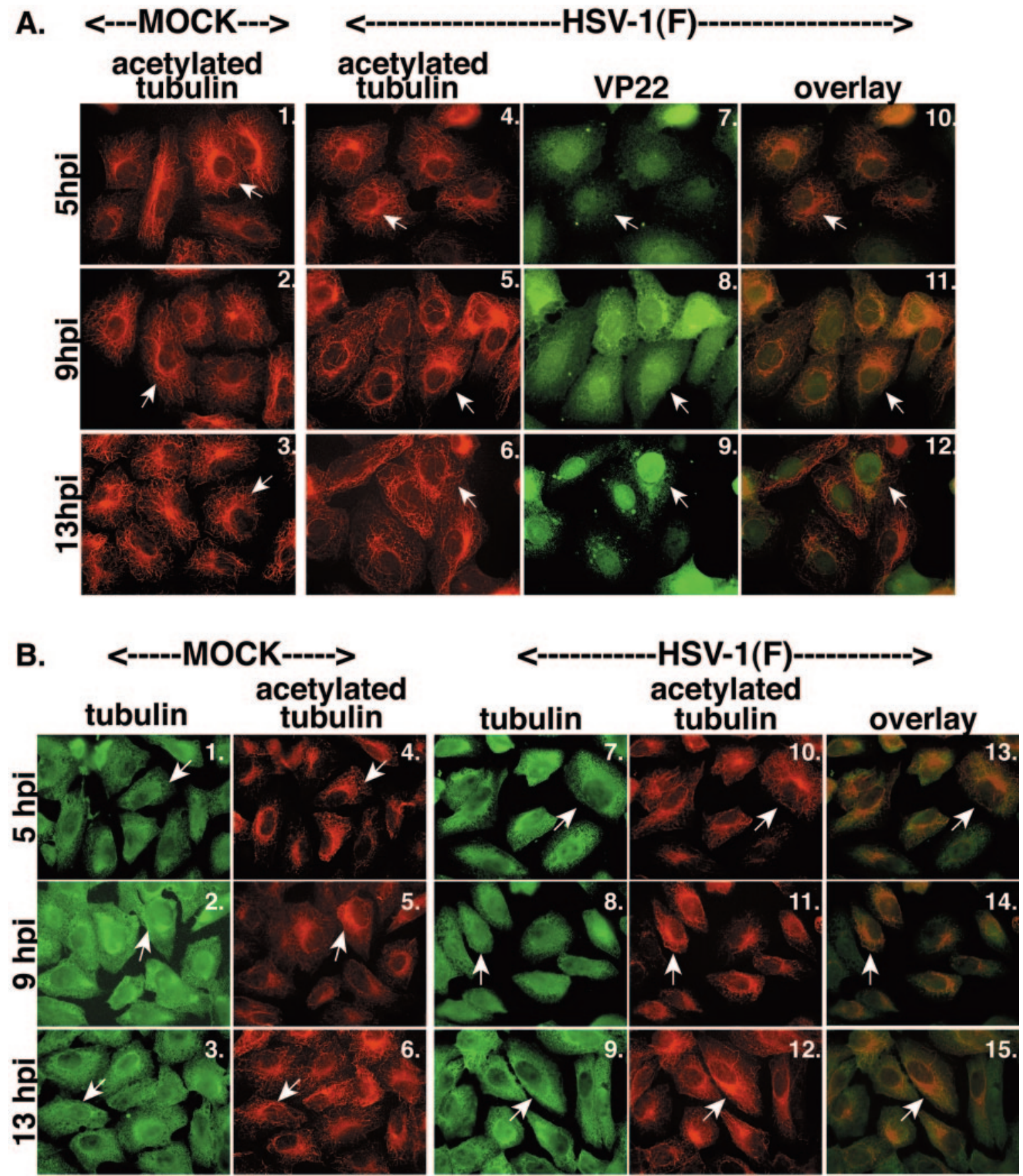

FIG. 8. Acetylated tubulin remains stable during HSV-1(F) infection. Duplicate sets of Vero cells were synchronously infected with HSV$1(\mathrm{~F})$ or mock infected, fixed at the indicated times, and analyzed by indirect immunofluorescence. Cells were double stained with anti-acetylated tubulin monoclonal (A and B) and anti-VP22 polyclonal (A) or anti- $\alpha$-tubulin polyclonal (B) antibody as described in Materials and Methods. Acetylated tubulin was visualized with Texas red. VP22 (A) and $\alpha$-tubulin polyclonal antibody (B) were visualized with FITC. Merged images (overlay) are also shown. Arrowheads indicate representative cells with stable perinuclear-juxtanuclear acetylated tubulin (Fig. 8A, panels 1 to 6, and Fig. 8B, panels 4 to 6 and 10 to 12) and corresponding cells with either VP22 (Fig. 8A, panels 7 to 9), or $\alpha$-tubulin (Fig. 8B, panels 1 to 3 and 7 to 9$)$.

As a control (data not shown), we also wanted to determine whether VP22 affected the stability of acetylated tubulin. During HSV-1(RF177) infection of Vero cells, acetylated tubulin appeared the same as that with HSV-1(F) at 5, 9, and $13 \mathrm{hpi}$ (data not shown). From this result, we can conclude that the absence of full-length VP22 does not affect the stability of acetylated tubulin during HSV-1 infection

In the second series of experiments, we wanted to assess changes in $\alpha$-tubulin and acetylated tubulin within the same infected cells (Fig. 8B). HSV-1(F) infections (MOI = 15 PFU/ 


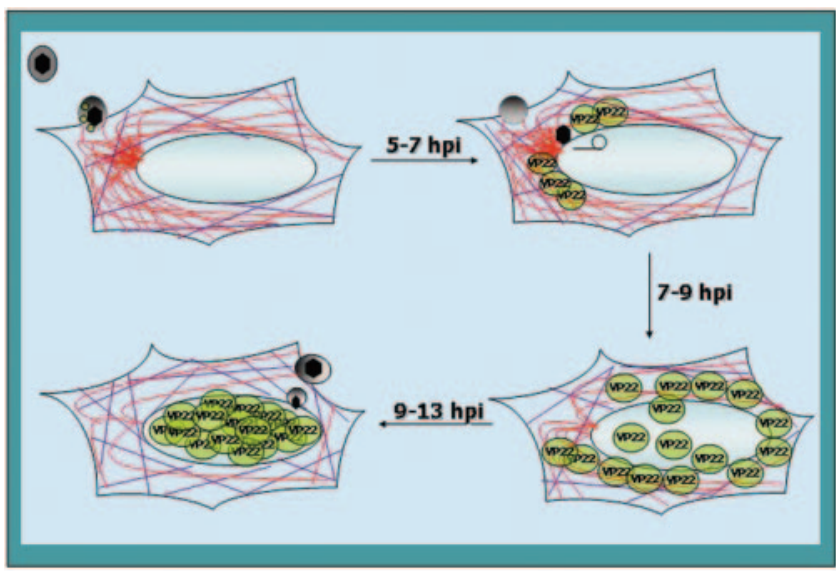

FIG. 9. Schematic representation of a model for microtubule reorganization and the nuclear localization of VP22 during HSV-1 infection in Vero cells. VP22 (green spheres) and other tegument proteins (gray sphere), including VP13/14, vhs, and VP16, are components of the incoming virion. At times prior to $5 \mathrm{hpi}$, dense MTOCs and both acetylated (purple) and nonacetylated (red) microtubules are observed in infected cells. The earliest detected VP22 is cytoplasmic and appears to accumulate at perinuclear-juxtanuclear locations, sometimes colocalizing with microtubules (approximately $7 \mathrm{hpi}$ ). As VP22 begins to be detected in nuclei, MTOCs decrease (approximately 9 hpi) until they completely disappear (approximately $13 \mathrm{hpi}$ ). At $13 \mathrm{hpi}$, essentially all VP22 observed is localized in nuclei. Throughout this process, acetylated microtubules remain intact.

cell) of Vero cells were analyzed at 5, 9, and $13 \mathrm{hpi}$ as described above, but during the indirect immunofluorescence analysis, we double stained the cells with a polyclonal antibody against $\alpha$-tubulin and the anti-acetylated tubulin monoclonal antibody. The polyclonal antibody specific for $\alpha$-tubulin stained a dense area just outside the nucleus of mock-infected cells (Fig. 8B, panels 1 to 3 ), reminiscent of MTOCs recognized by the anti$\alpha$-tubulin monoclonal antibody. However, this antibody appeared to have a high level of background staining. Nevertheless, it allowed us to show the placement of the acetylated tubulin staining over that of $\alpha$-tubulin (Fig. 8B, panels 13 to 15). The pattern of acetylated tubulin in the infected cells looked the same as that in mock-infected cells at all time points (Fig. 8, compare panel 4 to 6 and 10 to 12). Based on these findings, we conclude that acetylated tubulin does not undergo a change in appearance during HSV-1(F) infection when $\alpha$-tubulin is compared to acetylated tubulin by indirect immunofluorescence.

These experiments lead us to propose a model (Fig. 9) that acetylated tubulin remains stable and unchanging throughout the course of HSV-1(F) infection, while $\alpha$-tubulin changes its appearance due to its reorganization. Thus, it is conceivable that remaining areas of $\alpha$-tubulin staining at later times in infection may be the acetylated tubulin that does not reorganize. This stable acetylated tubulin (55) may prevent the cell from curling up during HSV-1-induced microtubule reorganization and thus might allow efficient viral infection.

\section{DISCUSSION}

The purpose of this study was to characterize the nuclear localization patterns of the VP13/14, vhs, and VP16 tegument proteins. In addition, we were interested in determining whether VP22 plays a role in HSV-1-induced microtubule reorganization and whether the nuclear localization of these other tegument proteins correlates with this event. Finally, we investigated which aspect of microtubules act to stabilize cells during their restructuring. The key features of our findings may be summarized as follows.

(i) VP13/14, vhs, and VP16 have nuclear localization kinetics different from that of VP22, which are independent of HSV-1-induced microtubule reorganization. This conclusion is based on the findings that all three of these tegument proteins localized to the nucleus between 5 and 9 hpi, which is much sooner than that observed for VP22. In addition, these proteins were detected in the nuclei of cells that possessed intact MTOCs, indicating that their nuclear translocation preceded HSV-1-induced microtubule reorganization. Although all four of the tegument proteins we characterized in this study can enter the cell with incoming virus, it should be noted that our analysis focused on de novo synthesized gene products. In our earlier study, we were unable to detect (incoming) VP22 at infection times prior to $3 \mathrm{hpi}$ (57). While we were able to detect incoming VP16 in nuclei at 2 hpi after infection of UV-inactivated virus, it required MOIs of at least $20 \mathrm{PFU}$ per cell (3). Both of VP16's known functions require that it reside in nuclei. First, VP16 is a transactivator for immediate early gene expression, and it migrates to nuclei soon after it enters the cell (11, 54, 58). VP16 of HSV-1 also serves an essential structural function in virion assembly (68) and is therefore needed for primary envelopment in nuclei (26). Surprisingly, VP16 does not appear to contain an obvious nuclear localization signal sequence and instead utilizes the HCF protein for its nuclear localization (42). For this reason, it makes sense that VP16's nuclear import is distinct from that of VP22. In our hands, we observed distinct localization patterns of VP22 and VP16 in infected, double-stained cells. However, indirect immunofluorescence analyses of VP16 and VP22 after transient transfection suggest that VP22 actually reorganizes VP16 within cells in the absence of other viral proteins (20). While the basis for the discrepancy between these studies is unknown, our results indicate that VP16 enters nuclei, presumably with the assistance of HCF, prior to VP22 during productive HSV-1 infection.

VP16 transactivation activity has been reported to be modulated by VP13/14 (47, 72, 73). This implies that VP16 and VP13/14 might be capable of associating with each other during infection. Likewise, VP16 and vhs were reported to have a direct physical association that allows VP16 to down regulate vhs activity $(36,43)$. This association of VP16 with vhs must occur at later times during infection, in contrast to the VP16VP13/14 transactivation association. Together, these observations that VP16 associates with both VP13/14 and vhs are consistent with our findings that these three proteins enter nuclei at the approximately the same time during synchronized infections. It seems clear from our work that the regulation of the nuclear import of VP22 during infection differs from that of VP16, VP13/14, and vhs.

During the course of these studies, we occasionally noticed slight VP13/14, VP22, and vhs staining just outside the nuclei at very late times in infection. One possibility explaining these observations is that they are abundant viral proteins which 
accumulate to high levels in infected cells and that the late perinuclear-juxtanuclear staining may represent protein aggregation $(50,51)$ during the fixing and permeabilization steps. We also cannot exclude the possibility that these patterns simply represent a minimal amount of background antibody binding by the viral Fc receptor $(34,57)$. An alternative, and perhaps more attractive, possibility is that the presence of these tegument proteins at these locations represents detection of cytoplasmic retegumentation during the potential reenvelopment process (reviewed in reference 26). The exact nature and biological significance of these intriguing structures is currently unknown and under further study. In any case, these minor effects do not impact the key conclusions of this study.

(ii) Optimal microtubule reorganization during HSV-1 infection requires full-length VP22. In retrospect, this conclusion does not seem surprising because we observed VP22 localizing with microtubules and MTOCs, in particular, during infection (38) and in VP22-expressing cell lines (38), while we (8) and others $(22,45)$ observed such associations in transfection studies. The implication here is that VP22 mainly functions to reorganize microtubules later, rather than earlier, in infection. This makes sense, as incoming capsids require an intact microtubule network to reach the nucleus (65). Since none of the other tegument proteins we tested localized to nuclei in a manner similar to that of VP22, we were interested in determining whether VP22 played a role in HSV-1-induced microtubule reorganization. That infection with our recombinant virus, which expresses only the amino-terminal 212 amino acids of VP22, resulted in a detectable delay in the kinetics of microtubule reorganization compared to that with wild-type virus and implicates full-length VP22 in the restructuring process. Importantly, when we repaired the $\mathrm{U}_{\mathrm{L}} 49$ locus in HSV1(RF177), infection with the resulting virus, HSV-1(RF177R) led to microtubule reorganization that was indistinguishable from that of HSV-1(F). It seems unlikely that other secondary attributes of the HSV-1(RF177) virus are responsible for this delay, since our original characterization of the virus showed that it accumulated all classes of viral polypeptides and it had the same single-step growth kinetics in Vero cells up to $13 \mathrm{hpi}$ as its wild-type parent, HSV-1(F) (56). The key phenotype we ascribed to HSV-1(RF177) was that it had a moderate spreading defect in Vero cells (56). Our new observation that HSV1(RF177)-infected cells have a delay in the reorganization of microtubules raises the intriguing possibility that perhaps the postponing of this restructuring gives rise to the small plaque phenotype. Consistent with this idea is our finding that prevention of microtubule reorganization by the addition of the stabilizing drug, paclitaxel (Taxol), decreases virus yield (38). We are now looking at HSV-1(RF177) infection times later than 13 hpi to determine the extent of the impact of having no full-length VP22 in this system.

It is also important to note that Elliott and colleagues observed that transiently expressed VP22 in COS- 1 cells treated with ethanol colocalized with cytoplasmic microtubules (22). Interestingly, their pattern of the colocalizing tubulin-VP22 complexes, although not the same as what Avitabile et al. reported (4), was different from nontransfected cells. In this same study (22), these authors also reported that a portion of VP22 in infected cells also colocalizes with microtubules in ethanol-treated cells. In a follow-up study, they used a series of
GFP-VP22 and GFP-tubulin fusion constructs to map the domain on VP22 to amino acids 108 to 212, which is required for the transient expression interaction in methanol-treated cells (45).

The association of HSV-1 tegument proteins with microtubules has been predicted to facilitate the migration of capsids to nuclear pores at the earliest times of infection $(16,44,64$, 65). However, our characterizations of the HSV-1(RF177) virus suggest a model in which VP22 functions mainly at the end stage of infection rather than at the earlier entry time (56). This would make sense if one of VP22's functions included reorganizing microtubules. The possibility now exists that another factor (a tegument protein?) present at early infection times acts to block VP22 from disrupting microtubules, so that capsids move freely to nuclear pores. Additional studies are necessary to elucidate the relationship between microtubules and VP22, as well as whether other factors are involved in this interaction.

Another interesting finding to come out of this study is that the $\Delta 212$ protein goes directly to nuclei as early as $5 \mathrm{hpi}$. The obvious conclusion is that its nuclear translocation is unregulated. The curious observation is that $\Delta 212$ appears to accumulate in nuclei and is not simply diffused throughout the cell. Since the kinetics of $\Delta 212$ nuclear translocation are strikingly similar to those of VP13/14, vhs, and VP16, it is tempting to speculate that one or more of these polypeptides associate with $\Delta 212$ to facilitate its entry or retention in nuclei. The biggest puzzle remaining is the finding that the nuclear import of $\Delta 212$ occurs in cells whose microtubule reorganization is delayed. This implies that the domains on VP22 responsible for its microtubule reorganizing activity and its nuclear import-retention are separable.

(iii) Acetylated microtubules remain stable throughout the course of HSV-1(F) and HSV-1(RF177) infections. We wish to propose a theory that acetylated tubulin may enable cells to be structurally stable during infection. We initiated this line of investigation as a result of our previous studies with the tubulin-depolymerizing agent nocodazole (38). Cells treated with nocodazole lost their flat shape and pulled away from the tissue culture dish. This general observation was also previously noted by the Avitabile group (4). Productive infection in these treated cells was inefficient in our hands. In our present study, we were curious to find out why such structural compromising of cells did not happen when HSV-1-induced microtubule reorganization occurred. Gianni Piperno (Mount Sinai School of Medicine) originally suggested that acetylated tubulin acts as a microtubule stabilizer during depolymerization with agents such as nocodazole (55). We observe that acetylated tubulin is present throughout infection; as (nonacetylated) $\alpha$-tubulin reorganizes, acetylated tubulin remains intact. The role of the intact acetylated tubulin might be to structurally maintain the cells in a flat morphology and to keep them attached to a tissue culture dish while still enabling microtubule reorganization to occur. It should also be pointed out that either transiently expressed VP22 or HSV-1 infection at approximately $16 \mathrm{hpi}$ was reported to increase the amount of immunoblot staining with an anti-acetylated tubulin antibody (22). Together, these observations support the idea that VP22 plays a role in microtubule reorganization while acetylated tubulin keeps cells stabilized during this process. An intriguing 
theory to pursue is that VP22 nuclear localization is also assisted by the acetylated tubulin. It is of interest to note that transiently transfected VP22 expressed in COS-1 cells correlates with enhanced immunoblotting with the anti-acetylated tubulin antibody (from Sigma) (22).

(iv) Proposal of a model for the regulation of VP22 subcellular localization during productive HSV-1 infection. Taking our findings together with earlier observations from our group $(8,38,56,57)$ and others (4) led us to come up with a model to describe the biology of VP22 in infected cells (Fig. 9). Prior to infection, cells contain structured microtubules with characteristic MTOCs, which also possess a detectable amount of acetylation. Between 5 and 7 hpi, the earliest VP22 observed accumulates in the cytoplasm in perinuclear-juxtanuclear regions, which include the area of the MTOC. At this time, the tegument proteins VP13/14, vhs, and VP16 have mostly translocated to nuclei. Microtubules begin to reorganize and MTOCs are lost between 7 and 9 hpi. During this time period, VP22 starts to translocate to nuclei, giving a diffuse appearance in indirect immunofluorescence studies. Evidence from our studies with the VP22 truncation virus indicates that VP22 contributes, at least in part, to the process of microtubule reorganization. By 13 hpi, microtubules have been completely restructured, no MTOCs are detected, and VP22 is completely nuclear. Importantly, acetylated microtubules remain unchanged throughout this entire process, potentially to support cellular structure. At this time, we do not know whether the acetylated microtubules we observe at late infection times represent those that existed prior to infection. It is conceivable that microtubule acetylation during HSV-1 infection is a dynamic process in which a steady-state level of acetylation is constantly maintained. Additional studies are required to assess whether microtubules which are actively undergoing reorganization are also capable of becoming acetylated.

The key question remaining is what function does microtubule reorganization play during productive HSV-1 infection? Elucidation of the mechanism through which VP22 associates with microtubules and how it utilizes microtubule reorganization to its advantage for nuclear localization will require the development of appropriate biochemical and molecular genetic systems.

\section{ACKNOWLEDGMENTS}

We thank Elise Morton for expert technical cell culture assistance and Gianni Piperno (Mount Sinai) for originally getting us excited about microtubule acetylation and providing microtubule-specific antibodies originally used in this study.

These studies were supported in part by a grant from the USPHS (AI 38873 to J.A.B.). A.K. is a predoctoral trainee and was supported in part by a USPHS Institutional Research Training Award (AI 07647). J.C.Y. was supported in part by an Undergraduate Research Fellowship from the Howard Hughes Medical Institute to Manhattan College, Riverdale, N.Y.

\section{REFERENCES}

1. Albright, A. G., and F. J. Jenkins. 1993. The herpes simplex virus UL37 protein is phosphorylated in infected cells. J. Virol. 67:4842-4847.

2. Aubert, M., and J. A. Blaho. 1999. The herpes simplex virus type 1 regulatory protein ICP27 is required for the prevention of apoptosis in infected human cells. J. Virol. 73:2803-2813.

3. Aubert, M., J. O'Toole, and J. A. Blaho. 1999. Induction and prevention of apoptosis in human HEp-2 cells by herpes simplex virus type 1. J. Virol. 73:10359-10370.

4. Avitabile, E., S. Di Gaeta, M. R. Torrisi, P. L. Ward, B. Roizman, and G.
Campadelli-Fiume. 1995. Redistribution of microtubules and Golgi apparatus in herpes simplex virus-infected cells and their role in viral exocytosis. J. Virol. 69:7472-7482.

5. Barker, D. E., and B. Roizman. 1990. Identification of three genes nonessential for growth in cell culture near the right terminus of the unique sequences of long component of herpes simplex virus 1. Virology 177:684 691

6. Batterson, W., and B. Roizman. 1983. Characterization of the herpes simplex virion-associated factor responsible for the induction of alpha genes. J. Virol. 46:371-377.

7. Blaho, J. A., C. Mitchell, and B. Roizman. 1994. An amino acid sequence shared by the herpes simplex virus 1 alpha regulatory proteins $0,4,22$, and 27 predicts the nucleotidylylation of the UL21, UL31, UL47, and UL49 gene products. J. Biol. Chem. 269:17401-17410.

8. Blouin, A., and J. A. Blaho. 2001. Assessment of the subcellular localization of the herpes simplex virus structural protein VP22 in the absence of other viral gene products. Virus Res. 81:57-68.

9. Brignati, M. J., J. S. Loomis, J. W. Wills, and R. J. Courtney. 2003. Membrane association of VP22, a herpes simplex virus type 1 tegument protein. J. Virol. 77:4888-4898.

10. Browne, H., S. Bell, T. Minson, and D. W. Wilson. 1996. An endoplasmic reticulum-retained herpes simplex virus glycoprotein $\mathrm{H}$ is absent from secreted virions: evidence for reenvelopment during egress. J. Virol. 70:43114316 .

11. Campbell, M. E., J. W. Palfreyman, and C. M. Preston. 1984. Identification of herpes simplex virus DNA sequences which encode a trans-acting polypeptide responsible for stimulation of immediate early transcription. J. Mol. Biol. 180:1-19.

12. Cunningham, C., A. J. Davison, A. R. MacLean, N. S. Taus, and J. D. Baines. 2000. Herpes simplex virus type 1 gene UL14: phenotype of a null mutant and identification of the encoded protein. J. Virol. 74:33-41.

13. Daikoku, T., K. Ikenoya, H. Yamada, F. Goshima, and Y. Nishiyama. 1998. Identification and characterization of the herpes simplex virus type 1 UL51 gene product. J. Gen. Virol. 79:3027-3031.

14. Daikoku, T., S. Shibata, F. Goshima, S. Oshima, T. Tsurumi, H. Yamada, Y. Yamashita, and Y. Nishiyama. 1997. Purification and characterization of the protein kinase encoded by the UL13 gene of herpes simplex virus type 2 . Virology 235:82-93.

15. Davis, L. I. 1995. The nuclear pore complex. Annu. Rev. Biochem. 64:865896.

16. Dohner, K., A. Wolfstein, U. Prank, C. Echeverri, D. Dujardin, R. Vallee, and B. Sodeik. 2002. Function of dynein and dynactin in herpes simplex virus capsid transport. Mol. Biol. Cell 13:2795-2809.

17. Donnelly, M., and G. Elliott. 2001. Fluorescent tagging of herpes simplex virus tegument protein VP13/14 in virus infection. J. Virol. 75:2575-2583.

18. Donnelly, M., and G. Elliott. 2001. Nuclear localization and shuttling of herpes simplex virus tegument protein VP13/14. J. Virol. 75:2566-2574.

19. Ejercito, P. M., E. D. Kieff, and B. Roizman. 1968. Characterization of herpes simplex virus strains differing in their effects on social behaviour of infected cells. J. Gen. Virol. 2:357-364.

20. Elliott, G., G. Mouzakitis, and P. O'Hare. 1995. VP16 interacts via its activation domain with VP22, a tegument protein of herpes simplex virus, and is relocated to a novel macromolecular assembly in coexpressing cells. J. Virol. 69:7932-7941.

21. Elliott, G., and P. O'Hare. 2000. Cytoplasm-to-nucleus translocation of a herpesvirus tegument protein during cell division. J. Virol. 74:2131-2141.

22. Elliott, G., and P. O'Hare. 1998. Herpes simplex virus type 1 tegument protein VP22 induces the stabilization and hyperacetylation of microtubules. J. Virol. 72:6448-6455.

23. Elliott, G., D. O'Reilly, and P. O'Hare. 1999. Identification of phosphorylation sites within the herpes simplex virus tegument protein VP22. J. Virol. 73:6203-6206.

24. Elliott, G., D. O'Reilly, and P. O'Hare. 1996. Phosphorylation of the herpes simplex virus type 1 tegument protein VP22. Virology 226:140-145.

25. Elliott, G. D., and D. M. Meredith. 1992. The herpes simplex virus type 1 tegument protein VP22 is encoded by gene UL49. J. Gen. Virol. 73:723-726.

26. Enquist, L. W., P. J. Husak, B. W. Banfield, and G. A. Smith. 1998. Infection and spread of alphaherpesviruses in the nervous system. Adv. Virus Res. 51:237-347.

27. Fenwick, M. L., and R. D. Everett. 1990. Inactivation of the shutoff gene (UL41) of herpes simplex virus types 1 and 2. J. Gen. Virol. 71:2961-2967.

28. Gershon, A. A., D. L. Sherman, Z. Zhu, C. A. Gabel, R. T. Ambron, and M. D. Gershon. 1994. Intracellular transport of newly synthesized varicellazoster virus: final envelopment in the trans-Golgi network. J. Virol. 68:63726390.

29. Gerster, T., and R. G. Roeder. 1988. A herpesvirus trans-activating protein interacts with transcription factor OTF-1 and other cellular proteins. Proc. Natl. Acad. Sci. USA 85:6347-6351.

30. Granzow, H., F. Weiland, A. Jons, B. G. Klupp, A. Karger, and T. C. Mettenleiter. 1997. Ultrastructural analysis of the replication cycle of pseudorabies virus in cell culture: a reassessment. J. Virol. 71:2072-2082.

31. Harms, J. S., X. Ren, S. C. Oliveira, and G. A. Splitter. 2000. Distinctions 
between bovine herpesvirus 1 and herpes simplex virus type 1 VP22 tegument protein subcellular associations. J. Virol. 74:3301-3312.

32. Herr, W., and M. A. Cleary. 1995. The POU domain: versatility in transcriptional regulation by a flexible two-in-one DNA-binding domain. Genes Dev. 9:1679-1693.

33. Hutchinson, I., A. Whiteley, H. Browne, and G. Elliott. 2002. Sequential localization of two herpes simplex virus tegument proteins to punctate nuclear dots adjacent to ICP0 domains. J. Virol. 76:10365-10373.

34. Johnson, D. C., M. C. Frame, M. W. Ligas, A. M. Cross, and N. D. Stow. 1988. Herpes simplex virus immunoglobulin G Fc receptor activity depends on a complex of two viral glycoproteins, gE and gI. J. Virol. 62:1347-1354.

35. Katan, M., A. Haigh, C. P. Verrijzer, P. C. van der Vliet, and P. O'Hare 1990. Characterization of a cellular factor which interacts functionally with Oct-1 in the assembly of a multicomponent transcription complex. Nucleic Acids Res. 18:6871-6880.

36. Knez, J., P. T. Bilan, and J. P. Capone. 2003. A single amino acid substitution in herpes simplex virus type 1 VP16 inhibits binding to the virion host shutoff protein and is incompatible with virus growth. J. Virol. 77:2892-2902.

37. Knopf, K. W., and H. C. Kaerner. 1980. Virus-specific basic phosphoprotein associated with herpes simplex virus type a (HSV-1) particles and the chromatin of HSV-1-infected cells. J. Gen. Virol. 46:405-414.

38. Kotsakis, A., L. E. Pomeranz, A. Blouin, and J. A. Blaho. 2001. Microtubule reorganization during herpes simplex virus type 1 infection facilitates the nuclear localization of VP22, a major virion tegument protein. J. Virol. 75:8697-8711.

39. Kristie, T. M., J. H. LeBowitz, and P. A. Sharp. 1989. The octamer-binding proteins form multi-protein-DNA complexes with the HSV alpha TIF regulatory protein. EMBO J. 8:4229-4238.

40. Kristie, T. M., and P. A. Sharp. 1993. Purification of the cellular C1 factor required for the stable recognition of the Oct-1 homeodomain by the herpes simplex virus alpha-trans-induction factor (VP16). J. Biol. Chem. 268:65256534.

41. Kwong, A. D., J. A. Kruper, and N. Frenkel. 1988. Herpes simplex virus virion host shutoff function. J. Virol. 62:912-921.

42. La Boissiere, S., T. Hughes, and P. O'Hare. 1999. HCF-dependent nuclear import of VP16. EMBO J. 18:480-489.

43. Lam, Q., C. A. Smibert, K. E. Koop, C. Lavery, J. P. Capone, S. P. Weinheimer, and J. R. Smiley. 1996. Herpes simplex virus VP16 rescues viral mRNA from destruction by the virion host shutoff function. EMBO J. 15: 2575-2581.

44. Mabit, H., M. Y. Nakano, U. Prank, B. Saam, K. Dohner, B. Sodeik, and U. F. Greber. 2002. Intact microtubules support adenovirus and herpes simplex virus infections. J. Virol. 76:9962-9971.

45. Martin, A., P. O'Hare, J. McLauchlan, and G. Elliott. 2002. Herpes simplex virus tegument protein VP22 contains overlapping domains for cytoplasmic localization, microtubule interaction, and chromatin binding. J. Virol. 76: 4961-4970.

46. McGeoch, D. J., M. A. Dalrymple, A. J. Davison, A. Dolan, M. C. Frame, D. McNab, L. J. Perry, J. E. Scott, and P. Taylor. 1988. The complete DNA sequence of the long unique region in the genome of herpes simplex virus type 1. J. Gen. Virol. 69:1531-1574.

47. McKnight, J. L., P. E. Pellett, F. J. Jenkins, and B. Roizman. 1987. Characterization and nucleotide sequence of two herpes simplex virus 1 genes whose products modulate alpha-trans-inducing factor-dependent activation of alpha genes. J. Virol. 61:992-1001.

48. McLean, G., F. Rixon, N. Langeland, L. Haarr, and H. Marsden. 1990 Identification and characterization of the virion protein products of herpes simplex virus type 1 gene UL47. J. Gen. Virol. 71:2953-2960.

49. Meredith, D. M., J. A. Lindsay, I. W. Halliburton, and G. R. Whittaker. 1991 Post-translational modification of the tegument proteins (VP13 and VP14) of herpes simplex virus type 1 by glycosylation and phosphorylation. J. Gen. Virol. 72:2771-2775.

50. Morrison, E. E., A. J. Stevenson, Y. F. Wang, and D. M. Meredith. 1998 Differences in the intracellular localization and fate of herpes simplex virus tegument proteins early in the infection of Vero cells. J. Gen. Virol. 79: 2517-2528.

51. Morrison, E. E., Y. F. Wang, and D. M. Meredith. 1998. Phosphorylation of structural components promotes dissociation of the herpes simplex virus type 1 tegument. J. Virol. 72:7108-7114.

52. O'Hare, P., and C. R. Goding. 1988. Herpes simplex virus regulatory ele- ments and the immunoglobulin octamer domain bind a common factor and are both targets for virion transactivation. Cell 52:435-445.

53. O'Toole, J. M., M. Aubert, A. Kotsakis, and J. A. Blaho. 2003. Mutation of the protein tyrosine kinase consensus site in the herpes simplex virus $1 \propto 22$ gene alters ICP22 posttranslational modification. Virology 305:153-167.

54. Pellett, P. E., J. L. McKnight, F. J. Jenkins, and B. Roizman. 1985. Nucleotide sequence and predicted amino acid sequence of a protein encoded in a small herpes simplex virus DNA fragment capable of trans-inducing alpha genes. Proc. Natl. Acad. Sci. USA 82:5870-5874.

55. Piperno, G., M. LeDizet, and X. J. Chang. 1987. Microtubules containing acetylated alpha-tubulin in mammalian cells in culture. J. Cell Biol. 104:289302 .

56. Pomeranz, L. E., and J. A. Blaho. 2000. Assembly of infectious Herpes simplex virus type 1 virions in the absence of full-length VP22. J. Virol. 74:10041-10054

57. Pomeranz, L. E., and J. A. Blaho. 1999. Modified VP22 localizes to the cell nucleus during synchronized herpes simplex virus type 1 infection. J. Virol. 73:6769-6781.

58. Post, L. E., S. Mackem, and B. Roizman. 1981. Regulation of alpha genes of herpes simplex virus: expression of chimeric genes produced by fusion of thymidine kinase with alpha gene promoters. Cell 24:555-565.

59. Preston, C. M., M. C. Frame, and M. E. Campbell. 1988. A complex formed between cell components and an HSV structural polypeptide binds to a viral immediate early gene regulatory DNA sequence. Cell 52:425-434.

60. Read, G. S., and N. Frenkel. 1983. Herpes simplex virus mutants defective in the virion-associated shutoff of host polypeptide synthesis and exhibiting abnormal synthesis of alpha (immediate early) viral polypeptides. J. Virol. 46:498-512.

61. Roizman, B., and D. M. Knipe. 2001. Herpes simplex viruses and their replication, p. 2399-2459. In D. M. Knipe, P. M. Howley, D. E. Griffin, R. A. Lamb, M. A. Martin, B. Roizman, and S. E. Straus (ed.), Fields virology, 4th ed. Lippincott Williams \& Wilkins, Philadelphia, Pa.

62. Salmon, B., C. Cunningham, A. J. Davison, W. J. Harris, and J. D. Baines. 1998. The herpes simplex virus type $1 \mathrm{U}_{\mathrm{L}} 17$ gene encodes virion tegument proteins that are required for cleavage and packaging of viral DNA. J. Virol. 72:3779-3788.

63. Smibert, C. A., and J. R. Smiley. 1990. Differential regulation of endogenous and transduced $\beta$-globin genes during infection of erythroid cells with a herpes simplex virus type 1 recombinant. J. Virol. 64:3882-3894.

64. Smith, G. A., and L. W. Enquist. 2002. Break ins and break outs: viral interactions with the cytoskeleton of mammalian cells. Annu. Rev. Cell Dev. Biol. 18:135-161.

65. Sodeik, B., M. W. Ebersold, and A. Helenius. 1997. Microtubule-mediated transport of incoming herpes simplex virus 1 capsids to the nucleus. J. Cell Biol. 136:1007-1021.

66. Spear, P. G., and B. Roizman. 1972. Proteins specified by herpes simplex virus. V. Purification and structural proteins of the herpesvirion. J. Virol. 9:143-159.

67. Stern, S., M. Tanaka, and W. Herr. 1989. The Oct-1 homoeodomain directs formation of a multiprotein-DNA complex with the HSV transactivator VP16. Nature 341:624-630.

68. Weinheimer, S. P., B. A. Boyd, S. K. Durham, J. L. Resnick, and D. R. O'Boyle II. 1992. Deletion of the VP16 open reading frame of herpes simplex virus type 1. J. Virol. 66:258-269.

69. Whiteley, A., B. Bruun, T. Minson, and H. Browne. 1999. Effects of targeting herpes simplex virus type $1 \mathrm{gD}$ to the endoplasmic reticulum and trans-Golgi network. J. Virol. 73:9515-9520.

70. Wilson, A. C., K. LaMarco, M. G. Peterson, and W. Herr. 1993. The VP16 accessory protein $\mathrm{HCF}$ is a family of polypeptides processed from a large precursor protein. Cell 74:115-125.

71. Xiao, P., and J. P. Capone. 1990. A cellular factor binds to the herpes simplex virus type 1 transactivator Vmw65 and is required for Vmw65-dependent protein-DNA complex assembly with Oct-1. Mol. Cell. Biol. 10:4974-4977.

72. Zhang, Y., and J. L. McKnight. 1993. Herpes simplex virus type 1 UL46 and UL47 deletion mutants lack VP11 and VP12 or VP13 and VP14, respectively, and exhibit altered viral thymidine kinase expression. J. Virol. 67: 1482-1492.

73. Zhang, Y., D. A. Sirko, and J. L. McKnight. 1991. Role of herpes simplex virus type 1 UL46 and UL47 in $\alpha$ TIF-mediated transcriptional induction: characterization of three viral deletion mutants. J. Virol. 65:829-841. 